\title{
Review Article \\ The Dual Role of Calcium as Messenger and Stressor in Cell Damage, Death, and Survival
}

\author{
Claudia Cerella, ${ }^{1}$ Marc Diederich, ${ }^{1}$ and Lina Ghibelli' ${ }^{2}$ \\ ${ }^{1}$ Laboratoire de Biologie Moléculaire et Cellulaire du Cancer, Hôpital Kirchberg, 9 rue Edward Steichen, \\ Luxembourg L-2540, Luxembourg \\ ${ }^{2}$ Dipartimento di Biologia, Università di Roma Tor Vergata, Via Ricerca Scientifica snc, Rome 00133, Italy
}

Correspondence should be addressed to Lina Ghibelli, ghibelli@uniroma2.it

Received 31 July 2009; Revised 15 November 2009; Accepted 6 January 2010

Academic Editor: Simone Fulda

Copyright () 2010 Claudia Cerella et al. This is an open access article distributed under the Creative Commons Attribution License, which permits unrestricted use, distribution, and reproduction in any medium, provided the original work is properly cited.

\begin{abstract}
$\mathrm{Ca}^{2+}$ is an important second messenger participating in many cellular activities; when physicochemical insults deregulate its delicate homeostasis, it acts as an intrinsic stressor, producing/increasing cell damage. Damage elicits both repair and death responses; intriguingly, in those responses $\mathrm{Ca}^{2+}$ also participates as second messenger. This delineates a dual role for $\mathrm{Ca}^{2+}$ in cell stress, making difficult to separate the different and multiple mechanisms required for $\mathrm{Ca}^{2+}$-mediated control of cell survival and apoptosis. Here we attempt to disentangle the two scenarios, examining on the one side, the events implicated in deregulated $\mathrm{Ca}^{2+}$ toxicity and the mechanisms through which this elicits reparative or death pathways; on the other, reviewing the role of $\mathrm{Ca}^{2+}$ as a messenger in the transduction of these same signaling events.
\end{abstract}

\section{Introduction: $\mathrm{Ca}^{2+}$ Signaling versus Deregulation in Life and Death}

$\mathrm{Ca}^{2+}$ is an ion involved in living processes in an atypical way: if other cations participate to enzyme activity without performing essential regulatory functions due to their abundance in all cell compartments, $\mathrm{Ca}^{2+}$ has a peculiar distribution, being present at very low levels in the cytosol of eukaryotic cells; this enables it to act as a messenger regulating cytosolic $\mathrm{Ca}^{2+}$-dependent enzymes and functions, when and where its local concentration raises above the steady-state level. For many decades the research on ion (and specifically $\mathrm{Ca}^{2+}$ ) roles in cell physiopathology was hampered by intrinsic technical difficulties. A big impulse came with the development of $\mathrm{Ca}^{2+}$-sensitive fluorescent probes $[1,2]$, that localize in specific cell compartments (cytosol, ER, and mitochondria) allowing separately and specifically evaluating and quantifying $\mathrm{Ca}^{2+}$ compartmentalization; and with the diffusion of instrumentations performing kinetic analyses, which allowed performing accurate and quantitative analysis of $\mathrm{Ca}^{2+}$ dynamics.

An efficient $\mathrm{Ca}^{2+}$ signaling implies maintenance of $\mathrm{Ca}^{2+}$ homeostasis, which requires mechanisms keeping cytosolic
$\mathrm{Ca}^{2+}$ concentration $\left(\left[\mathrm{Ca}^{2+}\right] \mathrm{c}\right)$ low and stable. These include active pumping against gradient by $\mathrm{Ca}^{2+}$ ATPases, enzymes present on the cytosolic side of plasma membrane and endoplasmic reticulum (ER) performing the high energyexpensive task of pumping $\mathrm{Ca}^{2+}$ out of the cytosol against gradient, or by ion exchangers (e.g., the $\mathrm{Na}^{+} / \mathrm{Ca}^{2+}$ ) [3]. Instead, signaling is exerted by discrete and highly controlled ER membrane channels, originating local $\mathrm{Ca}^{2+}$ rises possessing specific signaling roles, such as those regulated by the phospholipase C-inositol-3-phosphate pathway [3], or by cyclic (ADP-ribose) [4]. These local increases activate/deactivate $\mathrm{Ca}^{2+}$-sensitive enzymes, eliciting signal transduction chains aimed at controlling many diverse cell functions such as mitosis, or activation, or motility or apoptosis. As a feedback mechanism, the channels rapidly close due to local high $\left[\mathrm{Ca}^{2+}\right]$, which is rapidly extinguished by cytosolic buffering proteins, by the $\mathrm{Ca}^{2+}$-ATPases and by mitochondria, thus being in fact $\mathrm{Ca}^{2+}$ transients. To restore ER homeostasis, the partially emptied ER is replenished by $\mathrm{Ca}^{2+}$ entry from the extracellular space through controlled opening of plasma membrane channels (capacitative $\mathrm{Ca}^{2+}$ entry, see below [5]), or by $\mathrm{Ca}^{2+}$ released from mitochondria present in the vicinity of inositol-3-phosphate 
$\left(\mathrm{IP}_{3}\right)$ channels [6]. In the category of excitable cells, mainly neurons and myocytes, plasma membrane channels open following specific hormonal or physico-chemical stimulations, even in the absence of previous ER emptying, and possess signaling meaning of their own [7].

$\mathrm{Ca}^{2+}$ signaling requires the strict cooperation among the different cellular compartments and organelles, being in fact a highly sophisticated way of communication to maintain homeostasis and functionality of the whole cell. In particular, much attention is being given to the cooperation between ER and mitochondria, which interact through highly dynamic physical connections [8] containing abundant $\mathrm{Ca}^{2+}$-mediating transport systems [9]. These mediate the controlled reciprocal exchange of $\mathrm{Ca}^{2+}[10]$ aimed at modulating and supporting each other functions in the guise of an interorganellar symbiotic relationship [11-13].

The important implication of the low cytosolic $\mathrm{Ca}^{2+}$ concentration $\left(\left[\mathrm{Ca}^{2+}\right] \mathrm{c}\right)$ for cell homeostasis is that it must be maintained low against gradient (extracellular space and the internal $\mathrm{Ca}^{2+}$ stores such as ER, have 10,000 times as much $\left.\mathrm{Ca}^{2+}\right)$, since excess or deregulated $\left[\mathrm{Ca}^{2+}\right] \mathrm{c}$ pose cells in such a dramatic asset to be in fact cell-toxic. To this purpose, a wide range of mechanisms are displayed, including high capacity binding proteins, pumps and exchangers, and mitochondria, which possess a low affinity $\mathrm{Ca}^{2+}$ uniporter that sequesters cytosolic $\mathrm{Ca}^{2+}$ when it reaches the dangerous threshold of $500 \mathrm{nM}$, thus being a major detoxifying mechanism against $\mathrm{Ca}^{2+}$ overload [14].

Failure of the mechanisms devoted to maintain $\mathrm{Ca}^{2+}$ homeostasis produces generalized $\mathrm{Ca}^{2+}$ alterations, in turn producing rough cell damage, without involving specific signaling meaning; when strong, $\mathrm{Ca}^{2+}$ alterations cause cell death by necrosis [15-19].

What becomes clear after many years of intense studies about the role of $\mathrm{Ca}^{2+}$ in cell stress response and death, is that pathological $\mathrm{Ca}^{2+}$ alterations resulting from failure of homeostatic controls coexist with regulated $\mathrm{Ca}^{2+}$ signaling. The former produces rough damage that leads to cell repair, or apoptosis, or necrotic cell death, according to the intensity of the damage, whereas the latter constitutes a controlled cell response participating in survival or apoptotic pathway. This recommends careful analyses to separate active responses from passive changes.

\section{2. $\mathrm{Ca}^{2+}$ and Cell Damage}

2.1. $\mathrm{Ca}^{2+}$ as an Intrinsic Stressor. $\mathrm{Ca}^{2+}$ deregulation is a consequence of many different insults that end up altering $\mathrm{Ca}^{2+}$ homeostasis, causing and increasing damage to cells; for this reason, it may be defined as an "intrinsic stress," meaning that it is autoinduced by the cells as a consequence of an extrinsic stress of a different nature. The proteins controlling $\mathrm{Ca}^{2+}$ homeostasis are so many and so diverse that it is quite likely that any insult or physico-chemical alterations end up deregulating some of them, producing a set of reactions that may not properly be defined as signaling (since it has no physiological purposes), but it is nonetheless obliged by the presence of $\mathrm{Ca}^{2+}$-sensitive determinants. What is lacking in such instances is the coordination between the multiple pathways, which are instead casually activated, overlapping and superimposing one another, leading to cell collapse. The intrinsic $\mathrm{Ca}^{2+}$ stress may consist in either depletion of $\mathrm{ER} \mathrm{Ca}^{2+}$, or increase of cytosolic (or mitochondrial, or nuclear) $\mathrm{Ca}^{2+}$, or both.

2.2. Damage by $\mathrm{Ca}^{2+}$ Overload. When stress leads to $\mathrm{Ca}^{2+}$ overload, $\mathrm{Ca}^{2+}$-produced damage may reach levels sufficient to cause necrotic cell death [15-19]. Damage and death are due to excess stimulation of $\mathrm{Ca}^{2+}$-sensitive targets, which are numerous and concern key cellular functions: many enzymes that control supramolecular assembly, or degrading nucleic acids, lipids or proteins are $\mathrm{Ca}^{2+}$-sensitive. Among them are m-calpains, activated by high $\mathrm{Ca}^{2+}$ levels and implicated in cell death and in many neurological disturbances [20]; lipoxygenases, and a set of $\mathrm{Ca}^{2+}$ activated enzymes modifying arachidonic acid (AA) that are major actors of the inflammatory response, and also involved in apoptotic pathways [21]; phospholipases A2, which liberate AA from phospholipids, thus favoring, in the presence of high $\left[\mathrm{Ca}^{2+}\right] \mathrm{mt}$ mitochondria stress or collapse [22]; a set of DNAses, one of which historical interest for being the enzyme responsible for apoptotic laddering [23].

A major form of damage is caused by the intervention of mitochondria that, taking up the excess of cytosolic $\mathrm{Ca}^{2+}$ for scavenging purposes, may be subjected to stress and even collapse if it exceeds a physiological threshold, therefore increasing cell damage (see below) [14].

Another form of damage comes from energy failure, which starves $\mathrm{Ca}^{2+}$-ATPases that stop pumping $\mathrm{Ca}^{2+}$ against gradient from cytosol to ER, or to the extra-cellular environment, thus simultaneously producing cytosolic $\mathrm{Ca}^{2+}$ overload and $\mathrm{ER} \mathrm{Ca}^{2+}$ depletion.

Cytosolic $\mathrm{Ca}^{2+}$ overload is implicated in many serious human pathologies.

Excitotoxicity is a major cause of neuronal cell death; it develops as a consequence of problems occurring during neurotransmission, in instances of excess of excitatory signals, such as those from the neurotransmitter glutamate [24], or of deregulated signaling; this ends up impairing the tight control of $\mathrm{Ca}^{2+}$ channels, leading to $\mathrm{Ca}^{2+}$ overload [25] and eventually cell death and neurodegeneration.

Ischemic and anoxic stress produce deep changes in cell metabolism that, upon reoxygenation/reperfusion converge into a dramatic, toxic increase of cytosolic $\mathrm{Ca}^{2+}[26,27]$. Such changes include plasma membrane depolarization, which favors the opening of the plasma membrane $\mathrm{Ca}^{2+}$ channels thus promoting $\mathrm{Ca}^{2+}$ influx [28]; and acidification, which causes the inversion of the $\mathrm{Na}^{+} / \mathrm{Ca}^{2+}$ plasma membrane exchanger, which begins pumping $\mathrm{Ca}^{2+}$ within cells [29]. Mitochondria may buffer $\mathrm{Ca}^{2+}$ and rescue cells in instances of mild reperfusion stress; however, they paradoxically are the major cause of cell death in strong reperfusion stress [30], since the huge $\mathrm{Ca}^{2+}$ overload stimulate $\mathrm{Ca}^{2+}$ overcharging and collapse through phenomena of $\mathrm{Ca}^{2+}$ cycling (see below [31]). 
Due to the increasing evidence that most (if not all) pathologies involve, as etiological or concurrent agents, alterations of oxidative metabolism leading to oxidative stress, much attention was paid in the $80 \mathrm{~s}$ and $90 \mathrm{~s}$ to the mechanisms through which oxidative stress causes $\mathrm{Ca}^{2+}$ derangements. Although no definite picture is still delineated, some key points have been clarified. Oxidation and redox imbalance cause ER and plasma membrane $\mathrm{Ca}^{2+}$ channels malfunctions, since their oligomeric active form is controlled by disulfide bridges [32]; this increases $\left[\mathrm{Ca}^{2+}\right] \mathrm{c}$ and depletes $\left[\mathrm{Ca}^{2+}\right]$ er. Moreover, oxidative stress impairs the buffering capacity of mitochondria, lowering the internal $\mathrm{Ca}^{2+}$ threshold level of PTP opening $[9,33]$, thus depriving the cells of one of the major $\mathrm{Ca}^{2+}$ detoxifying mechanisms.

All of these derangements are especially critical for neurons, where $\mathrm{Ca}^{2+}$ is crucial to neuronal functions [34], implying that they possess more controlling steps that can be altered. Moreover, cell death is most devastating for tissues rich in post-mitotic cells, such as cardiomyocytes or neurons, which are difficult to replace; indeed, most neurodegenerative conditions are characterized by neuronal death caused by $\mathrm{Ca}^{2+}$ overload [34]. The scenario is even more dramatic considering that the organs that mostly depend on post-mitotic, $\mathrm{Ca}^{2+}$-sensitive cells are heart and brain, whose failure causes immediate death of the organism.

2.3. $\mathrm{Ca}^{2+}$ Overload in Mitochondria. Mitochondria are very important for intracellular $\mathrm{Ca}^{2+}$ homeostasis and signaling, acting in fact as pivot of intracellular $\mathrm{Ca}^{2+}$ communications. Any $\mathrm{Ca}^{2+}$ overload exceeding the cytosolic threshold of $500 \mathrm{nM}$ involve mitochondrial participation [14]. Mitochondria possess low affinity $(500 \mathrm{nM}) \mathrm{Ca}^{2+}$ uniporters that allow the accumulation of large amount of $\mathrm{Ca}^{2+}$ within the mitochondrial matrix, which constitutes a high capacity $\mathrm{Ca}^{2+}$ reservoir, allowing buffering $\left[\mathrm{Ca}^{2+}\right] \mathrm{c}$ increases over $500 \mathrm{nM}$ $[9,14]$. This mitochondria ability plays an important role in cell homeostasis and cell signaling, because it help extinguishing cytosolic $\mathrm{Ca}^{2+}$ signals [35]. The resulting $\left[\mathrm{Ca}^{2+}\right] \mathrm{mt}$ increase modulates mitochondrial activity (i.e., increases ATP production $[9,11,12])$; moreover, overcharged mitochondria helps refilling ER after physiological $\mathrm{Ca}^{2+}$ emptying (e.g., after $\mathrm{IP}_{3}$-mediated signalling [13]). In instances of mild $\left[\mathrm{Ca}^{2+}\right] \mathrm{c}$ increases originating from stressing events, potentially toxic $\mathrm{Ca}^{2+}$ is sequestered within mitochondria, and then released after the stress is over: in this instance mitochondria play a prosurvival role. However, if the amount of sequestered $\mathrm{Ca}^{2+}$ exceeds mitochondrial capacity, it leads to collapse through opening of the permeability transition pores (PTP, formerly referred to as megachannel) $[18,19]$. Since PTP is a multi-ion channel, the consequence is that the captured $\mathrm{Ca}^{2+}$ ions are dissipated, creating new cytosolic $\mathrm{Ca}^{2+}$ increase, which can be in turn taken up by new intact mitochondria [18]. This creates cycles of $\mathrm{Ca}^{2+}$ uptake and dissipation, recruiting more mitochondria, up to a sort of mitochondrial suicide cascade. This phenomenon was named $\mathrm{Ca}^{2+}$ cycling [18], and raised much interest in the 80s; the interest then declined because it did not support a clear physiological role, being rather considered a futile cycle, because it does not help cells to survive.
Nowadays, a re-evaluation of this mechanism suggests that $\mathrm{Ca}^{2+}$ cycling provides a physiological advantage [10]: PTP opening by itself causes release of cytochrome $c$ (even in the absence of an upstream canonical apoptotic signaling such as Bax translocation [19, 36, 37]), which in turn may activate caspases and promote apoptosis [18], thus transforming a necrotic cell death into a more physiocompatible apoptosis. It seems worth mentioning here that localized phenomena of mitochondria $\mathrm{Ca}^{2+}$ cycling may have a pro-apoptotic signaling meaning since local and controlled small episodes of cytochrome $c$ release act as initiators of the intrinsic pathway of apoptosis [38] (see below).

Mitochondria can adjust their cellular localization by moving around the microtubular network [39]; it is tempting to hypothesize that they reach positions required to perform $\mathrm{Ca}^{2+}$ detoxification, or to modulate specific signaling events, that is, extinguish some and exacerbating others, according to need. As an example, acute oxidative stress induces the reorganization of mitochondrial pattern from pan-cytoplasmatic, to peri-nuclear (Ghibelli, unpublished observation), possibly buffering excess $\mathrm{ER} \mathrm{Ca}^{2+}$ leakage due to oxidations. This scenario suggests that local $\mathrm{Ca}^{2+}$ increases of a stress nature, even of a small extent, may trigger an apoptotic signaling via recruitment of mitochondria.

2.4. Damage by $\mathrm{Ca}^{2+}$ Depletion (ER Stress). When referring to intracellular $\mathrm{Ca}^{2+}$ depletion, the emphasis goes to emptying of ER, which elicits what was recently recognized as ER stress [40]. ER stress is caused by different disturbances affecting ER homeostasis, such as protein malfolding, glucose starvation, disturbance of membrane turnover/synthesis, or of protein trafficking, which all lead to ER vesiculation and loss of function [40]. $\mathrm{Ca}^{2+}$ plays a key role in maintaining ER structure, since the flat shape of the cisternae is actively kept by bridges constituted by high capacity $\mathrm{Ca}^{2+}$ binding proteins such as calreticulin, calsequestrin, and calnexin [41]; upon ER $\mathrm{Ca}^{2+}$ emptying, $\mathrm{Ca}^{2+}$ binding is lost, the bridges weaken and ER resumes the low energy spherical shape of lipids droplets in acqueous solution, thus losing function. ER stress, as any other stress, can evolve into repair or apoptosis.

In the first instance, the stress response implies upregulation of stress proteins such as GRP78, a major luminal ER protein [42] that plays a central role as ER stress sensor displaying multiple functions. It coordinates the activation of other proteins implicated in ER stress, such as ATF6 [43], a transcription factor transactivating prosurvival genes whose promoters containing ER stress response elements (ERSEs) [44]. GRP78 also promotes removal by autophagy of the altered portions of ER by controlling the correct formation of autophagosome [45]. Multifaceted is its ability to prevent apoptosis [42, 46]: a fraction of GRP78 is present as a transmembrane ER protein, exposing a cytoplasmic domain able to directly interact and form an inhibitory complex with caspase-7 and/or caspase-12 [42, 47]; GRP78 limits the proapoptotic activation of c-Jun N-terminal kinase (JNK) [35], normally acting as a transducer of ER stress [48]; in addition, cell-free studies suggest a direct ability of GRP78 to control mitochondria, by inhibiting cytochrome $c$ release [47]. 
If damage is severe, it triggers apoptosis. The mechanism for ER stress-induced apoptosis is still not completely clarified. Big emphasis was given to caspase-12, which is activated in ER membranes in instances of disruption of ER $\mathrm{Ca}^{2+}$ homeostasis or accumulation of unfolded proteins in the ER lumen of mice cell models. Caspase-12 initiates apoptosis either in a mitochondrial-independent fashion [49] or recruiting and activating mediators of the intrinsic pathway of apoptosis [50]. This led to consider caspase-12 as the general transducer of ER damage. However, caspase 12 is present only in rodents, and to-date no functional caspase12 was identified in human cells (which in fact possess only a pseudo-gene), nor a functionally equivalent protein. While the search for a human equivalent of caspase 12 is still active (especially concerning a possible role for caspase-4 [51]), other caspase-independent scenarios, have been explored to describe the transduction of the ER stress to apoptosis via mitochondria. Recently, Klee et al. [52] provided evidence that $\mathrm{Ca}^{2+}$ mobilization from the ER is required to initiate the mitochondrial death pathway, by cooperating with the effectors of ER stress surveillance machinery IREa/TRAF2; according to this model, $\mathrm{Ca}^{2+}$ promotes the JNK proapoptotic pathway through a complex set of steps involving the Bcl-2 family.

\section{3. $\mathrm{Ca}^{2+}$ and Cell Death}

3.1. Historical Perspective. When the regulated, physiological mode of cell death, apoptosis, came into the general interest, the involvement of de-regulated $\mathrm{Ca}^{2+}$ rises as causative agent of apoptosis was sought for, in the view that apoptosis was a sort of "petit necrosis;" in particular, a $\mathrm{Ca}^{2+} / \mathrm{Mg}^{2+}$ dependent DNAse was hypothesized, considering that DNA laddering was the earliest apoptotic marker of a biochemical nature to be widely accepted. The issue however never came to a definite picture, because if an increase of $\left[\mathrm{Ca}^{2+}\right] \mathrm{c}$ was indeed occurring in some examples of apoptosis, such as the paradigmatic model of rat thymocytes treated with corticosteroids [53], in many other instances it was a drop in overall $\mathrm{Ca}^{2+}$ level the event that promotes apoptosis [54].

The paradox of this dual, opposite role of $\mathrm{Ca}^{2+}$ in apoptosis occupied several years of research. Thapsigargin (THG), a (still) popular inducer of apoptosis, is an irreversible poison of ER $\mathrm{Ca}^{2+}$-ATPases (SERCA), thereby inducing a transient increase in cytosolic $\mathrm{Ca}^{2+}$ and a sustained depletion of the $\mathrm{ER} \mathrm{Ca}^{2+}$ pool [55]; since the two events occur simultaneously, it is quite difficult to assess the specific contribution of one or the other to apoptosis. If the early studies were taking for granted that the apoptogenic event was the increase of $\left[\mathrm{Ca}^{2+}\right] \mathrm{c}$, it was later shown that in many instances intracellular $\mathrm{Ca}^{2+}$ buffering did not abrogate, but even increased, THG-induced apoptosis, demonstrating that also $\mathrm{ER} \mathrm{Ca}^{2+}$ depletion was an apoptogenic event $[56,57]$.

In fact, in most instances $\left[\mathrm{Ca}^{2+}\right] \mathrm{c}$ rises in apoptosis are not rough event, but precise signaling steps, such as, for example, the $\mathrm{Ca}^{2+}$-dependent proteases calpains [58] or calmodulin [59]. The notion of apoptotic $\mathrm{Ca}^{2+}$ signaling evolved, with not small effort, together with the awareness that apoptosis is not a "petit necrosis" but a regular signal transduction chain, occurring in functioning cells, ending up with coordinate cell demise instead of activation, or mitosis, or transcription.

To-date, the issue of the actual role of $\mathrm{Ca}^{2+}$ in cell death is still debated; the different contributions of the different cells (e.g., excitable versus non-excitable; dividing versus post-mitotic; tumor versus normal) and of the different apoptogenic treatments (stress or physiologic; allowing or not protein neosynthesis, etc.) produce a whole continuum of variations, and render it hard to interpret the thousands of studies on the topic. However, some generalizations can be attempted: ER $\mathrm{Ca}^{2+}$ depletion may elicit apoptosis through the ER stress pathway $[57,60]$; rough, stress-induced $\mathrm{Ca}^{2+}$ overloads produce necrosis $[17,19,61]$; regulated $\mathrm{Ca}^{2+}$ increases play a role as signaling events in the intrinsic apoptotic pathway [62-65].

The poor knowledge of the role of $\mathrm{Ca}^{2+}$ in apoptosis, which is perhaps surprising considering that $\mathrm{Ca}^{2+}$ dynamics were among the first alterations proposed as causative of apoptosis, is also due to other, more intrinsic problems. Among them the fact that $\mathrm{Ca}^{2+}$ transients are very much localized in terms of space (i.e., cytosolic micro-domains) and time (seconds), and it is very easy to miss them even with sophisticated technologies. Also the asynchrony of the apoptotic process hampers the analyses: even homogeneous cultured cells initiate apoptosis at different moments after stimulation, overlapping different phases and rendering inappropriate any biochemical analysis performed in bulk. These problems were overcome with technological approaches allowing analysis at the single cell level $[1,2]$, that is, living cell imaging and flow cytometry, which are beginning to shed light on the process, helping to separate different phases and different subregions of $\mathrm{Ca}^{2+}$ signaling $[1,2,64,65]$.

3.2. Stress-Induced Apoptosis: A General View. It is now well established that the intracellular apoptotic signaling evolves through at least two different pathways, triggered by ligand stimulation of death receptor (extrinsic pathway), or by cell damage (intrinsic pathway) [66]. The extrinsic pathway is a typical signal transduction consisting of proteinprotein interaction and conformational changes from the very beginning, being induced by a molecular event such as ligand-receptor interaction and culminating with caspase activation and cell dismantling. The intrinsic pathway is instead induced not by molecular, but by physicochemical events, implying that (a) sensor(s) of micro-environmental alterations or cell damage must be activated to promote the apoptotic signal [67]; afterwards, a molecular signal transduction chain of events similar to the extrinsic pathway is activated, also culminating with caspase activation. Sensors are proteins that are modified by physico-chemical alterations such as $\mathrm{pH}$, redox equilibrium, or $\mathrm{Ca}^{2+}$ levels, thus acquiring the ability to trigger a molecular signal cascade. The most upstream molecular event of the intrinsic pathway is the translocation of Bax, which moves to mitochondria and induces mitochondrial outer membrane permeabilization (MOMP). The difficulty of finding molecular events upstream of Bax activation suggested that Bax itself might 
be a sensor of physico-chemical alterations. Indeed, recent reports indicate that Bax activation can occur via direct oxidation of cysteines $[68,69]$, or via proteolytical activation by calpains [70].

3.3. $\mathrm{Ca}^{2+}$ Control of Cytochrome $c$ Release. It is emerging a pre- or early-commitment phase of the intrinsic apoptotic pathway, occurring before MOMP, during which potential apoptotic signals, mostly relying on $\mathrm{Ca}^{2+}$ messages, are selected and amplified by cross-talk between ER and mitochondria [61] (Figure 1). MOMP is a set of different phenomena allowing release (or leakage, see below) of apoptogenic factors such as cytochrome $c$, SMAC/diablo, AIF, through mitochondrial membrane pores. Cytochrome $c$ received most attention for its ability to nucleate the apoptosome and to initiate the caspase cascade; its release occurs through at least two different mechanisms, the apoptosis-specific Bax-based pore, and the PTP channel, both of which can be modulated by $\mathrm{Ca}^{2+}$ in a very different way.

The relation between $\mathrm{Ca}^{2+}$ and cytochrome $c$ release via Bax consists of a feed-forward amplification loop between ER and mitochondria: local high concentrations of $\mathrm{Ca}^{2+}$ (such as those created by the $\mathrm{Ca}^{2+}$ efflux from $\mathrm{IP}_{3}$ channels) favor the release of cytochrome $c$ from mitochondria through Bax pores $[62,71]$ on the one side; on the other, cytosolic cytochrome $c$ increases $\mathrm{Ca}^{2+}$ levels in the vicinity of $\mathrm{IP}_{3}$ channels on ER [38] by fixing them in the open configuration after a signaling stimulus, thus transforming a transient flux into a sustained one [38]. As a result of this interplay, small cytosolic cytochrome $c$ leakage may promote secondary and massive releases (i.e., that required for apoptosome nucleation), via local $\mathrm{Ca}^{2+}$ messages [38]. This provides a rationale to previous reports indicating that small amounts of cytochrome $c$ are released from mitochondria as a very early step of apoptosis, with the goal of expanding the signal [72]. Intriguingly, the $\mathrm{Ca}^{2+}$ sensitivity of $\mathrm{Bax}$ mitochondrial pores seems to be limited to the intrinsic pathway: when Bax is activated by the extrinsic pathway via t-Bid [73] (i.e., death receptor stimulation in type 2 cell), the Bax pores are insensitive to $\mathrm{Ca}^{2+}$ modulation [62]. This indicates that active Bax is different according to the route of activation (i.e., damage versus t-Bid), suggesting that multiple, alternative mechanisms for Bax activation may exist, possibly leading to different effects on the folding and functions of the protein $[68,70,73]$.

PTP opening is an automatic response to excess $\left[\mathrm{Ca}^{2+}\right] \mathrm{mt}$, which causes the interaction between the inner mitochondrial membrane complex adenine nucleotide translocator (ANT) and the outer mitochondrial membrane complex voltage-dependent anion channels (VDAC), leading to the formation of the membrane-spanning PTP pore. Cyclophilin D (Cyp-D) is a component of PTP resident in the mitochondrial matrix, which is activated by high $\left[\mathrm{Ca}^{2+}\right] \mathrm{mt}$, favoring PTP opening by lowering the $\mathrm{Ca}^{2+}$ threshold required for ANT-VDAC interaction [74-76]. In instances of mitochondrial $\mathrm{Ca}^{2+}$ overload, inhibitors of Cyp$\mathrm{D}$ activation, such as cyclosporins, contrast PTP opening and the eventual cell death, therefore exerting a net cell protective effect, which is often used in therapies to limit immune deficiencies or neurodegenerations $[76,77]$.

The mechanism of cytochrome $c$ release via PTP opening, which was historically the first mechanism proposed, is still unclear from the molecular and functional point of view (Figure 1). In fact, there is a topological problem. In apoptosis cytochrome $c$ is liberated from its natural position on the outer side of the internal mitochondrial membrane to the intermembrane space; thus, it requires pores in the outer membrane to be released, whereas pores that span the two membranes, such as PTP, would lead to the release of molecules residing in the mitochondrial matrix. To explain cytochrome $c$ release via PTP, it may be hypothesized that PTP may cause mitochondrial membrane perturbations that allow cytochrome $c$ (and other factors) to leak rather than be specifically released. In such instances, the gross alterations caused by PTP-mediated ionic redistribution will be necrogenic [78], even if cytosolic relocalization of cytochrome $c$ may circumstantially activate caspases. Conceivably, the extent of PTP may determine the final outcome, and apoptosis or necrosis may follow according to the strength of PTP. Indeed, Cyp-D inhibitors are often reported to prevent cell death by necrosis. As an alternative mechanism of cytochrome $c$ relase via PTP, it was suggested that a VDAC-only channel may form on the outer membrane, with the help, but without the physical participation, of ANT, thus connecting the cytosol not with the matrix, as in the canonical PTP, but with the intermembrane space, thus allowing cytochrome $c$ release. This model is supported by experiments performed in liver mitochondria from mice knock out for ANT isoforms [79], where the release of cytochrome $c$ following an apoptogenic stimulus still occurred, but the susceptibility to $\mathrm{Ca}^{2+}$ alterations in the mitochondrial matrix was reduced. In this instance ANT, a sensor of $\mathrm{Ca}^{2+}$ through its interaction with Cyp-D, plays the regulatory function to transduce $\mathrm{Ca}^{2+}$ alterations to VDAC, promoting its oligomerization and the formation of pores mediating release of cytochrome $c$.

Bax pores and PTP are different in molecular, mechanistic and functional term. However, they cooperate in some examples of apoptosis to achieve cytochrome $c$ release. This implies physical interaction between Bax and PTP components [80], such as Cyp-D or ANT [81]. The two mechanisms of cytochrome $c$ release also coparticipates in the same induction pathway in a different temporal relationship, that is, a mild stress-induced PTP opening first causes a small cytochrome $c$ leakage, which stimulates via $\mathrm{Ca}^{2+}$ modulation (see above) a second intense Baxmediated release sufficient for caspase activation. The cooperation between the two pores (and the two pathways) also provides a mechanistic explanation to the established but still unexplained finding that $\mathrm{Bcl}-2$, though not modulating PTP directly [74], all the same provides protection to cells against necrosis [82].

3.4. Control of $\mathrm{Ca}^{2+}$ by the $\mathrm{Bcl}-2$ Family. The pro-apoptotic protein Bax exerts its functions by inserting into membranes and forming pores. Very well described is the anchoring to mitochondrial membrane, where Bax forms, perhaps 


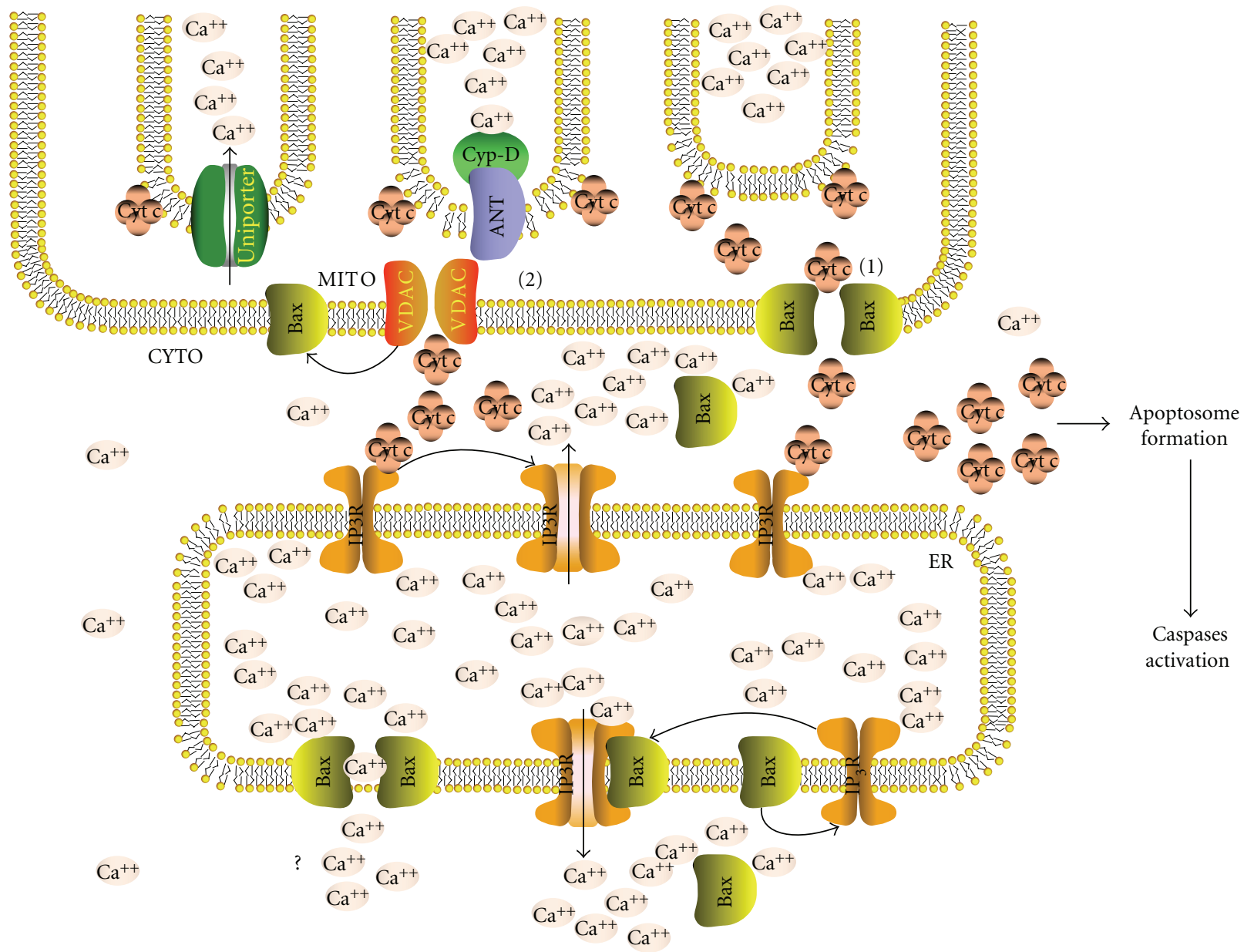

FIGURE 1: $\mathrm{Ca}^{2+}$ signals between ER and mitochondria coordinate the precommitment phase of apoptosis: amplification loops between Bax activation and $\mathrm{Ca}^{2+}$ release from ER amplify cytochrome $c$ release to a level sufficient for apoptosome nucleation and caspase activation. Cytochrome $c$ released by Bax (1) or VDAC (2) mitochondrial pores magnifies $\mathrm{Ca}^{2+}$ efflux from $\mathrm{IP}_{3}$ channels; the consequent local high cytosolic $\mathrm{Ca}^{2+}$ recruits Bax (via calpain?) to mitochondria or ER membrane, stimulating more cytochrome $c$ release and more $\mathrm{Ca}^{2+}$ efflux, respectively.

with adjuvant proteins, pores of a size large enough to allow passage of diffusible pro-apoptotic proteins such as cytochrome $c$ or SMAC [83-85]; the anti-apoptotic role of the cognate Bcl-2, which integrates into mitochondrial membranes also in healthy cells, is believed to be the prevention of Bax pore forming, perhaps due to the extra protein domain (BH4) shared by all anti-apoptotic members of the family. It is now emerging that Bax and Bcl-2 play a similar role also in the ER membranes, where they would prevent or favor, respectively, $\mathrm{Ca}^{2+}$ leakage to the cytosol.

Bcl-2 is found within ER membranes of healthy cells, where it prevents $\mathrm{Ca}^{2+}$ leaking from ER $[63,86]$; as the mechanism involved, it was proposed that Bcl-2 may work as a pump additional to the SERCAs [56], and/or to prevent $\mathrm{IP}_{3}$ channels opening [87].

In apoptosis, Bax translocates not only to mitochondria, but also to ER membranes $[63,88]$, where it favors $\mathrm{Ca}^{2+}$ release from the ER lumen $[62,63]$, possibly after oligomerization [71]; similar evidence was shown for the cognate pro-apoptotic Bak $[63,88]$. The mechanism through which Bax (and Bak) favors ER $\mathrm{Ca}^{2+}$ release is currently debated. Recent cell-free studies have shown that Bax forms small pores, compatible with multi-ion passage, on membranes [89], thus possibly directly allowing $\mathrm{Ca}^{2+}$ leakage. Other studies indicate an indirect role, that is, favoring $\mathrm{IP}_{3}$ channels opening $[90,91] . \mathrm{Ca}^{2+}$ release from ER in turn favors the recruitment of more Bax molecules from the cytosol to ER membranes [88], thus amplifying the $\mathrm{Ca}^{2+}$-dependent apoptotic signal [71]. Thus, the pro-apoptotic functions of Bax and Bak are not limited to mitochondria, but consist of a dual concerted role played at an earlier pre-commitment step at the level of ER membranes, promoting $\mathrm{Ca}^{2+}$ movements; and at a later step in mitochondria to promote MOMP and the release of the apoptotic factors. It remains to be clarified if the mechanism of Bax translocation to ER in preapoptosis occurs with the same mechanism as mitochondrial translocation, that is, if there is a role for $\mathrm{t}$-Bid or other BH3only proteins of the $\mathrm{Bcl}-2$ family; moreover, it is still unclear 
if Bax domains involved in promoting $\mathrm{ER} \mathrm{Ca}^{2+}$ leakage coincide with those required for releasing the apoptotic factors from mitochondria.

3.5. Calpain and Apoptosis. A role for the cysteine proteases calpains, which are activated by $\mathrm{Ca}^{2+}$ increase, was investigated since the earlier studies of apoptotic signaling, considering that (a) cytosolic $\mathrm{Ca}^{2+}$ overload was then considered as the main mediator of apoptosis [92], and (b) apoptosis might be conceivably executed by coordinate protein dismantling (which was later demonstrated for caspases) $[58,93]$. The focus was placed on the known calpain target fodrin [94], the protein bridging plasma membrane with the cortical actin cytoskeleton; it was hypothesized that fodrin degradation might destabilize the cytoskeleton-membrane asset and promote plasma membrane blebbing [95], one of the earliest apoptotic features described [96]; however, such evidences have not been confirmed; actually, calpain activation seems rather inhibiting plasma membrane blebbing (De Nicola et. al, in preparation).

Nowadays, many pieces of evidence show that calpains are required for apoptosis in some systems [97-100], being dispensable (or not involved) in others [101]; when calpains are involved, they act at a very early step, upstream of caspases $[100,102]$, thus participating to the commitment phase of signaling rather than to the execution. The notion that the form of calpain involved in apoptosis is $\mathrm{m}$-calpain [103], the one also involved in cell stress [20] and that requires high $(\mathrm{mM}) \mathrm{Ca}^{2+}$ levels (as opposed to $\mu$-calpain, involved in cell signaling, and requiring lower, $\mu \mathrm{M}$ doses) was very important because it allowed linking environmental alterations to apoptosis via $\mathrm{Ca}^{2+}$ overload. The molecular role for calpain in promoting apoptosis is still under investigation. Perhaps the most clear-cut hint is the calpainmediated proteolytic Bax activation $[70,104]$, one of the few mechanisms so far proposed for direct Bax activation by cell damage [104-106]. Two mitochondrial calpains cooperate in the release of a truncated active form of AIF (tAIF) thus promoting apoptosis: a matrix m-calpain cleaves AIF [107]; and a transmembrane $\mu$-calpain cleaves VDAC, promoting the formation of Bax-VDAC pores on the outer mitochondrial membrane and the release of tAIF [108].

A complex interplay between calpain and caspases occurs in apoptosis. Calpain have been proposed to proteolytically activate some caspases $[100,109-112]$; paradoxically, caspases may also be degraded by calpains [113], which in such instances would act to prevent, rather than promote, apoptosis; the factors influencing this discrepant behavior have not been clarified.

\section{4. $\mathrm{Ca}^{2+}$ and the Stress Response}

4.1. Generalities. Stress consists of any physico-chemical alteration of cell environment that interferes with cell functioning, potentially or actually producing damage. Stress elicits active cell responses that, according to cell type, and to type and extent of damage, aim at cell survival (cellprotective and/or cell-reparative stress response, such as the heat shock response) or cell death (apoptosis).
Stress responses are specific for a given type of alteration/damage: heat, oxidation, hypoxia, starvation, all trigger the synthesis or activation of molecular determinants adequate to cope with the specific type of damage; for example, heat shock will induce synthesis of molecular chaperones to cope with exposure of hydrophobic residues of proteins [114]; oxidative stress will induce the synthesis/activation of anti-oxidant enzymes or molecules [115]; hypoxia promotes anaerobic metabolism [116]; starvation promotes the disassembly of whole cell areas that are digested by autophagy [117], in order to recycle the building blocks for housekeeping purposes. This specificity of response limits the cross-resistance between different stress, even though a partial overlapping exist.

A brief/mild insult is often sufficient to trigger protective responses but not to produce damage. This protects the cells from a second, more severe insult of the same type, thus producing transient tolerance to further stress, as occurring, for example, during thermotolerance [118]. Treatments with important clinical relevance, such as ischemia preconditioning, that is a short anoxic treatment that is protective towards a more severe ischemia, and whose mechanisms are still to be elucidated at the molecular level, seem to depend on $\mathrm{Ca}^{2+}$ signaling [119]. $\mathrm{Ca}^{2+}$ participates as second messenger to such defensive, reparative, or survival pathways, propagating the cell-protective signals.

High $\left[\mathrm{Ca}^{2+}\right] \mathrm{c}$ is involved in the stimulation of the autophagic response through the activation of calcium/ calmodulin-dependent kinase-b that inhibits mTOR [120], the main negative regulator of authophagic processes in mammals, with the goal of eliminating cellular areas that may be damaged by $\mathrm{Ca}^{2+}$ overload.

4.2. $\mathrm{Ca}^{2+}$ in Cell Survival. In addition to these specific stress responses, cells are capable to build up survival pathways that render them less prone to apoptosis, thus promoting cell survival whatever the type of damage; this especially occurs in cells that reside in highly stressing environments, such as inflammatory or immune cells while exerting their functions [121], or transformed cells undergoing tumor progression [122], process in which cells carrying apoptosis-resistant mutations are favored by natural selection.

$\mathrm{Ca}^{2+}$ is involved in pro-survival or anti-apoptotic pathways, such as the activation of protein kinase $\mathrm{C}$, whose many isoforms play pivot roles in coordinating survival cell responses [123].

Capacitative $\mathrm{Ca}^{2+}$ entry (CCE) is $\mathrm{Ca}^{2+}$ influx from the extracellular environment through specific and tightly controlled plasma membrane channels $[4,5]$. CCE only transiently crosses the cytosol, its aims being rather the replenishment of ER, after it was partially emptied by signaling events such as cyclic ADP-ribose- [4] or $\mathrm{IP}_{3}$ mediated opening of ER $\mathrm{Ca}^{2+}$ channels [5]. CCE poorly alters cytosolic homeostasis, but prevents ER vesiculation due to $\mathrm{Ca}^{2+}$ emptying, thus being a net cell-protective event.

Recently, another mechanism of $\mathrm{Ca}^{2+}$ influx is being considered, namely the noncapacitative $\mathrm{Ca}^{2+}$ influx (NCCE) [124], a non-store-operated mechanism that allows $\mathrm{Ca}^{2+}$ entry through plasma membrane channels that are different 


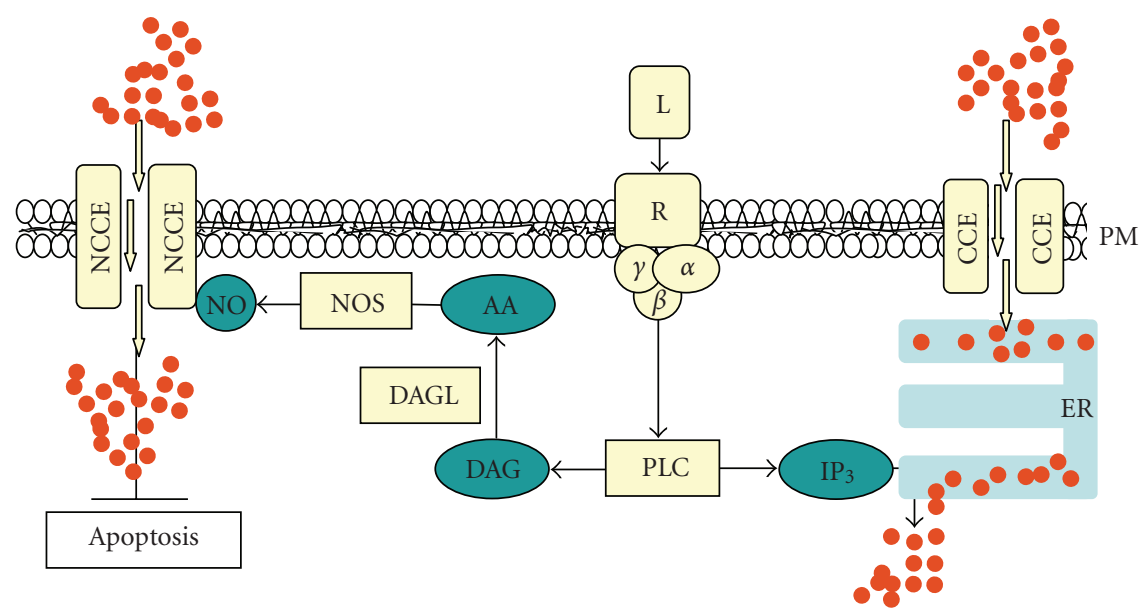

FIGURE 2: Capacitative and noncapacitative $\mathrm{Ca}^{2+}$ entry. Ligand $(\mathrm{L})$ stimulation of G-protein $(\alpha \beta \gamma)$-coupled receptor (R) activates phospholipase C (PLC) to produce diacylglycerol (DAG) and inositol-3-phosphate $\left(\mathrm{IP}_{3}\right)$. $\mathrm{IP}_{3}$ (right side) causes ER Ca ${ }^{2+}$ emptying, eliciting a capacitative $\mathrm{Ca}^{2+}$ entry (CCE) through plasma membrane (PM), aimed at refilling ER of $\mathrm{Ca}^{2+}$ restoring ER homeostasis. DAG (left side) is processed to arachidonic acid (AA) by DAG lipase (DAGL), stimulating NOS to produce NO, which activates $\mathrm{Ca}^{2+}$ entry through PM by a noncapacitative $\mathrm{Ca}^{2+}$ entry (NCCE), priming specific signaling including anti-apoptotic pathways. CCE and NCCE differ in protein composition [124]. Red dots symbolize $\mathrm{Ca}^{2+}$.

from those of $\mathrm{CCE}$ from the molecular and regulative point of view. As depicted in Figure 2, NCCE, as CCE, occurs as a response to receptor stimulation implying Gprotein and phospholipase C (PLC) but, unlike CCE, it does not respond to $\mathrm{IP}_{3}$-induced ER emptying; instead, it results from the processing of diacylglycerol (the other product of inositol-bis-phosphate cleavage by PLC), which promotes a signal transduction chain culminating with NCCE assembly. Interestingly, NCCE occurs also in nonexcitable cells. Even though mechanisms and functions are still poorly characterized, it is clear that $\mathrm{Ca}^{2+}$ entry via NCCE has a signaling function, possibly implying the control of survival pathways. Interestingly, it requires production of $\mathrm{NO}$, a molecule that is involved in many survival pathways [125], including a strict interrelationship with protein kinase $\mathrm{C}$ [124]. Agents promoting cell survival such as magnetic fields reduce stress-induced apoptosis by increasing $\mathrm{Ca}^{2+}$ influx $[126,127]$, involving NCCE rather than CCE (Cerella and Ghibelli, in preparation).

4.3. Stand-By Mechanisms. The decision between cell repair or demise of damaged cells is a choice between the risk of mal-repair, leading to stabilize mutations and potentially preserve precancerous cells, versus loss of viable cells performing useful functions, which must be expensively replaced. Even though the former risk is definitely worse than the latter, mechanisms aiming at avoiding unnecessary loss of precious cells have evolved. To this purpose, it is important that damaged cells do not initiate apoptosis before attempting to repair the damage: this is actively achieved by damaged cells via the set-up of reversible standby scenarios, during which apoptotic signaling is transiently kept at bay. One of such standby mechanisms implies that potentially apoptogenic stress conditions such as $\mathrm{H}_{2} \mathrm{O}_{2}$ treatment cause the transient inhibition of glycolysis mediated by the reversible ADP-ribosylation of glyceraldehyde-3-phosphatedehydrogenase (GAPDH) [128]; this inactivates ER $\mathrm{Ca}^{2+}$ ATPases, which are fed by glycolytic ATP [129], thus decreasing ER $\mathrm{Ca}^{2+}$ while increasing $\left[\mathrm{Ca}^{2+}\right] \mathrm{c}$ and impairing $\mathrm{Ca}^{2+}$-mediated cell signaling. Many pieces of evidence from the literature show that cells with partial $\mathrm{Ca}^{2+}$-depleted ER cannot initiate apoptosis [130-132], and indeed, during the standby period of glycolysis block, apoptosis cannot initiate [128]. Starting at around 90 minutes after recovering from $\mathrm{H}_{2} \mathrm{O}_{2}$ stress, glycolysis resumes [128], $\mathrm{ER} \mathrm{Ca}^{2+}$ increases, and $\left[\mathrm{Ca}^{2+}\right] \mathrm{c}$ is reduced [64]; only then $\mathrm{H}_{2} \mathrm{O}_{2}$-induced apoptosis begins [128]; (Cerella et al., in preparation). Similar findings were reported also for other, oxidation-unrelated apoptogenic agents, strongly supporting the scenario according to which (a) $\mathrm{Ca}^{2+}$ signaling is required for stress-induced apoptosis [64], and (b) ER is the initiator of the apoptotic signaling, since the standby phase seems to prevent ER from amplifying apoptotic signal and mitochondrial recruitment. A model representing the relationship between apoptogenic, repair and standby signals in damaged cells is shown in Figure 3.

\section{Conclusions}

The relationship between $\mathrm{Ca}^{2+}$ and cell death has a long and complex story. It was a reasonably simple task when the goal was describing how strongly deregulated intracellular $\mathrm{Ca}^{2+}$ may cause the passive cell death by necrosis. The scenario became very much complex when the increasing information of the mechanisms of $\mathrm{Ca}^{2+}$-mediated cell signaling in general, and apoptotic signaling in particular, begun to merge. Figure 4 depicts the different roles that $\mathrm{Ca}^{2+}$ alterations, as an intrinsic stressor, play in the survival or death of damaged cells, aiming at separating $\mathrm{Ca}^{2+}$ deregulation from pro-apoptotic $\mathrm{Ca}^{2+}$ signaling. Perhaps 


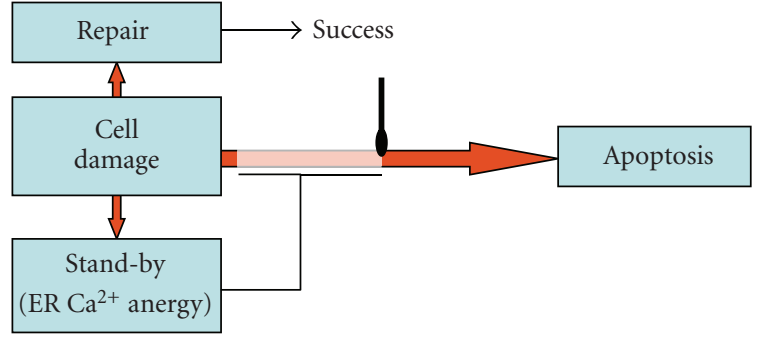

FIgURE 3: Temporary ER $\mathrm{Ca}^{2+}$ anergy avoid loss of repairable cells. Cell damage elicits repair and apoptosis as well as standby periods (red arrows). ER $\mathrm{Ca}^{2+}$ anergy is temporarily achieved via ADPribosylation of GAPDH, glycolysis block and starvation of $\mathrm{Ca}^{2+}$ ATPases, and hampers apoptotic signal transduction at the ER signaling stage. After resumption of glycolysis and $\mathrm{ER} \mathrm{Ca}^{2+}$ activity, the apoptotic signal is allowed to proceed, unless successful repair has occurred in the meantime.

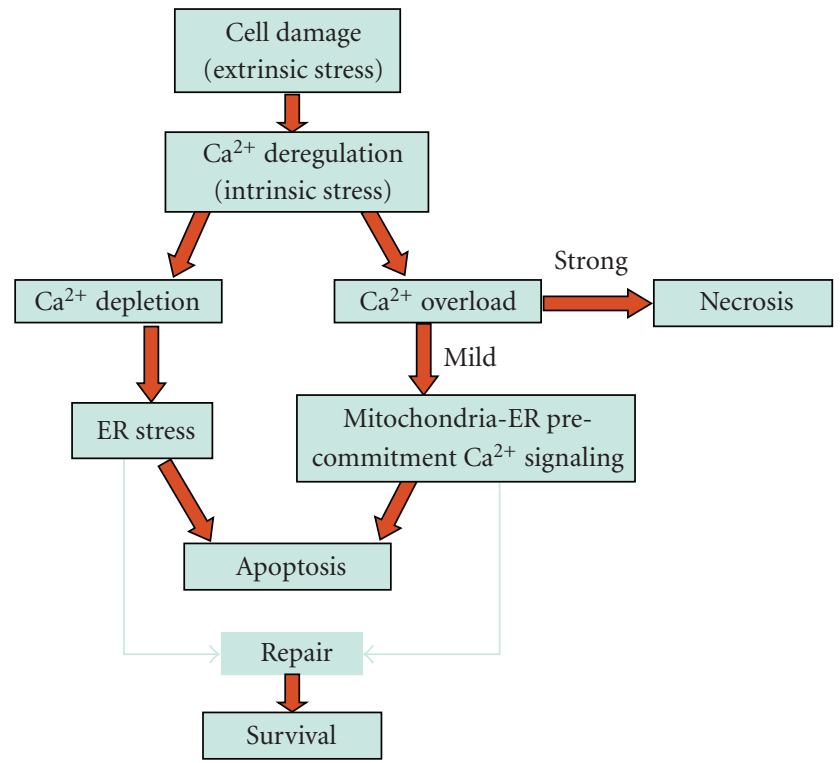

FIGURE 4: $\mathrm{Ca}^{2+}$ signaling in survival and apoptosis versus deregulation of $\mathrm{Ca}^{2+}$ homeostasis as necrogenic event.

the hottest topic to-date in this field is the role that ER, and the $\mathrm{Ca}^{2+}$ messages it exchanges with mitochondria, plays in the amplification of the apoptotic signal, ending up with the promotion of MOMP and the trigger of the commitment phase of the intrinsic apoptotic signaling. The amplification loops created by the concerted action of ER, Bax, $\mathrm{IP}_{3}$ channels and cytochrome $c$ with $\mathrm{Ca}^{2+}$ signals, spanning ER and mitochondria via cytosol, as depicted in Figure 1 , are beginning to define a novel precommitment phase of apoptosis. This is a very important issue because, unlike the extrinsic apoptotic pathway, which has been very well characterized at the molecular level since many years, the molecular events of the intrinsic pathway upstream of MOMP are poorly understood. From the functional point of view, a precommitment phase might have the role of selecting, among the pro-apoptotic signals deriving from cell damage, the ones that have to be finalized in cell death, thus avoiding unnecessary cell loss. Unlike receptor-induced apoptosis, before commitment to damage-induced apoptosis cells must check the extent of the damage, and the possibility to repair it, before engaging the apoptotic signaling and commit suicide. To this purpose, different signals reporting the nature and the extent of the damage must merge into a mainstream signal that actually allows the onset of apoptosis, which in molecular terms coincides with MOMP. Many evidences allow proposing the fascinating scenario according to which ER plays as a pivot that receives the damage signals and select those that actually deserve ending up in apoptosis.

The acknowledgement of a $\mathrm{Ca}^{2+}$-dependent pre-commitment apoptotic phase would place $\mathrm{Ca}^{2+}$-related events among the earliest of apoptosis, which would make the closing of a circle that begun almost 20 years ago, when $\mathrm{Ca}^{2+}$ as an intrinsic stressor was considered as "the" mediator of apoptosis.

\section{Abbreviations \\ AA: Arachidonic acid \\ AIF: Apoptosis inducing factor \\ ANT: Adenine nucleotide translocator \\ CCE: Capacitative calcium entry \\ ER: $\quad$ Endoplasmic reticulum \\ GAPDH: Glycerhaldehyde-3-phospahate dehydrogenase \\ $\mathrm{IP}_{3}$ : Inositol-3-phosphate \\ MOMP: Mitochondrial outer membrane permeabilization \\ NCCE: Non-capacitative calcium entry \\ PLC: Phospholipase C \\ PTP: $\quad$ Permeability transition pore \\ SERCA: Sarcoplasmic/endoplasmic reticulum calcium ATPases \\ THG: Thapsigargin \\ VDAC: Voltage-dependent anion channels.}

\section{Acknowledgments}

The first author is a recipient of a postdoctoral Télévie grant. Research at the third and the second authors' labs are financially supported in part by "Recherches Scientifiques Luxembourg" association. The second author's lab is also financed by "Recherche Cancer et Sang" foundation, by "Een Haerz fir kriibskrank Kanner" association, by the Action Lions "Vaincre le Cancer" association, and by Télévie Luxembourg.

\section{References}

[1] G. Grynkiewicz, M. Poenie, and R. Y. Tsien, "A new generation of $\mathrm{Ca}^{2+}$ indicators with greatly improved fluorescence properties," Journal of Biological Chemistry, vol. 260, no. 6, pp. 3440-3450, 1985.

[2] A. Chiesa, E. Rapizzi, V. Tosello, et al., "Recombinant aequorin and green fluorescent protein as valuable tools in the study of cell signalling," Biochemical Journal, vol. 355, no. 1, pp. 1-12, 2001. 
[3] M. J. Berridge, M. D. Bootman, and H. L. Roderick, "Calcium signalling: dynamics, homeostasis and remodelling," Nature Reviews Molecular Cell Biology, vol. 4, no. 7, pp. 517-529, 2003.

[4] H. C. Lee, "Cyclic ADP-ribose: a calcium mobilizing metabolite of NAD ", Molecular and Cellular Biochemistry, vol. 138, no. 1-2, pp. 229-235, 1994.

[5] J. W. Putney Jr., L. M. Broad, F.-J. Braun, J.-P. Lievremont, and G. St. J. Bird, "Mechanisms of capacitative calcium entry," Journal of Cell Science, vol. 114, no. 12, pp. 2223-2229, 2001.

[6] R. Malli, M. Frieden, M. Trenker, and W. F. Graier, "The role of mitochondria for $\mathrm{Ca}^{2+}$ refilling of the endoplasmic reticulum," Journal of Biological Chemistry, vol. 280, no. 13, pp. 12114-12122, 2005.

[7] E. Carafoli, "Calcium homeostasis in excitable cells," Biochemical Society Transactions, vol. 16, no. 4, pp. 519-520, 1988.

[8] G. Csordás, C. Renken, P. Várnai, et al., "Structural and functional features and significance of the physical linkage between ER and mitochondria," Journal of Cell Biology, vol. 174, no. 7, pp. 915-921, 2006.

[9] G. Csordás and G. Hajnóczky, "SR/ER-mitochondrial local communication: calcium and ROS," Biochimica et Biophysica Acta, vol. 1787, no. 11, pp. 1352-1362, 2009.

[10] V. Y. Ganitkevich, "The role of mitochondria in cytoplasmic $\mathrm{Ca}^{2+}$ cycling," Experimental Physiology, vol. 88, no. 1, pp. 9197, 2003.

[11] R. G. Hansford, "Dehydrogenase activation by $\mathrm{Ca}^{2+}$ in cells and tissues," Journal of Bioenergetics and Biomembranes, vol. 23, no. 6, pp. 823-854, 1991.

[12] P. R. Territo, V. K. Mootha, S. A. French, and R. S. Balaban, " $\mathrm{Ca}^{2+}$ activation of heart mitochondrial oxidative phosphorylation: role of the F0/F1-ATPase," American Journal of Physiology, vol. 278, no. 2, pp. C423-C435, 2000.

[13] S. Arnaudeau, W. L. Kelley, J. V. Walsh Jr., and N. Demaurex, "Mitochondria recycle $\mathrm{Ca}^{2+}$ to the endoplasmic reticulum and prevent the depletion of neighboring endoplasmic reticulum regions," Journal of Biological Chemistry, vol. 276, no. 31, pp. 29430-29439, 2001.

[14] G. E. N. Kass and S. Orrenius, "Calcium signaling and cytotoxicity," Environmental Health Perspectives, vol. 107, supplement 1, pp. 25-35, 1999.

[15] N. Kaiser and I. S. Edelman, "Calcium dependence of glucocorticoid induced lymphocytolysis," Proceedings of the National Academy of Sciences of the United States of America, vol. 74, no. 2, pp. 638-642, 1977.

[16] N. Kaiser and I. S. Edelman, "Calcium dependence of ionophore A23187 induced lymphocyte cytotoxicity," Cancer Research, vol. 38, no. 11, part 1, pp. 3599-3603, 1978.

[17] J. de Leiris and F. Boucher, "Ischemic myocardial cell necrosis: calcium overload or oxygen free-radicals?" Revista Portuguesa de Cardiologia, vol. 9, no. 2, pp. 153-158, 1990.

[18] C. Richter, "Pro-oxidants and mitochondrial $\mathrm{Ca}^{2+}$ : their relationship to apoptosis and oncogenesis," FEBS Letters, vol. 325, no. 1-2, pp. 104-107, 1993.

[19] T. Qian, B. Herman, and J. J. Lemasters, "The mitochondrial permeability transition mediates both necrotic and apoptotic death of hepatocytes exposed to Br-A23187," Toxicology and Applied Pharmacology, vol. 154, no. 2, pp. 117-125, 1999.

[20] F. Demarchi and C. Schneider, "The calpain system as a modulator of stress/damage response," Cell Cycle, vol. 6, no. 2, pp. 136-138, 2007.
[21] D. G. Tang, Y. Q. Chen, and K. V. Honn, "Arachidonate lipoxygenases as essential regulators of cell survival and apoptosis," Proceedings of the National Academy of Sciences of the United States of America, vol. 93, no. 11, pp. 5241-5246, 1996.

[22] A. A. Caro and A. I. Cederbaum, "Role of intracellular calcium and phospholipase A2 in arachidonic acid-induced toxicity in liver cells overexpressing CYP2E1," Archives of Biochemistry and Biophysics, vol. 457, no. 2, pp. 252-263, 2007.

[23] D. J. McConkey, P. Hartzell, P. Nicotera, and S. Orrenius, "Calcium-activated DNA fragmentation kills immature thymocytes," FASEB Journal, vol. 3, no. 7, pp. 1843-1849, 1989.

[24] C. S. Colwell and M. S. Levine, "Metabotropic glutamate receptor modulation of excitotoxicity in the neostriatum: role of calcium channels," Brain Research, vol. 833, no. 2, pp. 234-241, 1999.

[25] R. Sattler and M. Tymianski, "Molecular mechanisms of calcium-dependent excitotoxicity," Journal of Molecular Medicine, vol. 78, no. 1, pp. 3-13, 2000.

[26] T. J. Higgins, D. Allsopp, and P. J. Bailey, "Calcium- and anoxia-induced damage of cardiac myocytes in culture," Biochemical Society Transactions, vol. 8, no. 5, p. 583, 1980.

[27] C. Steenbergen, E. Murphy, L. Levy, and R. E. London, "Elevation in cytosolic free calcium concentration early in myocardial ischemia in perfused rat heart," Circulation Research, vol. 60, no. 5, pp. 700-707, 1987.

[28] W. E. Cascio, H. Yang, T. A. Johnson, B. J. Muller-Borer, and J. J. Lemasters, "Electrical properties and conduction in reperfused papillary muscle," Circulation Research, vol. 89, no. 9, pp. 807-814, 2001.

[29] B. N. Eigel and R. W. Hadley, "Antisense inhibition of $\mathrm{Na}^{+} / \mathrm{Ca}^{2+}$ exchange during anoxia/reoxygenation in ventricular myocytes," American Journal of Physiology, vol. 281, no. 5, pp. H2184-H2190, 2001.

[30] A. P. Halestrap, "Calcium, mitochondria and reperfusion injury: a pore way to die," Biochemical Society Transactions, vol. 34, no. 2, pp. 232-237, 2006.

[31] A. Dorio, C. Cerella, M. De Nicola, M. D’Alessio, G. Gualandi, and L. Ghibelli, "Non-apoptogenic $\mathrm{Ca}^{2+}$-related extrusion of mitochondria in anoxia/reoxygenation stress," Annals of the New York Academy of Sciences, vol. 1099, pp. 512-515, 2007.

[32] L. C. Hool and B. Corry, "Redox control of calcium channels: from mechanisms to therapeutic opportunities," Antioxidants and Redox Signaling, vol. 9, no. 4, pp. 409-435, 2007.

[33] G. Hajnóczky, G. Csordás, S. Das, et al., "Mitochondrial calcium signalling and cell death: approaches for assessing the role of mitochondrial $\mathrm{Ca}^{2+}$ uptake in apoptosis," Cell Calcium, vol. 40, no. 5-6, pp. 553-560, 2006.

[34] D. G. Nicholls, "Mitochondrial calcium function and dysfunction in the central nervous system," Biochimica et Biophysica Acta, vol. 1787, no. 11, pp. 1416-1424, 2009.

[35] C. Walsh, S. Barrow, S. Voronina, M. Chvanov, O. H. Petersen, and A. Tepikin, "Modulation of calcium signalling by mitochondria," Biochimica et Biophysica Acta, vol. 1787, no. 11, pp. 1374-1382, 2009.

[36] D. B. Zorov, C. R. Filburn, L.-O. Klotz, J. L. Zweier, and S. J. Sollott, "Reactive oxygen species (ROS)-induced ROS release: a new phenomenon accompanying induction of the mitochondrial permeability transition in cardiac myocytes," Journal of Experimental Medicine, vol. 192, no. 7, pp. 10011014, 2000. 
[37] F. B. Mullauer, J. H. Kessler, and J. P. Medema, "Betulinic acid induces cytochrome $\mathrm{c}$ release and apoptosis in a Bax/Bakindependent, permeability transition pore dependent fashion," Apoptosis, vol. 14, no. 2, pp. 191-202, 2009.

[38] D. Boehning, R. L. Patterson, L. Sedaghat, N. O. Glebova, T. Kurosaki, and S. H. Snyder, "Cytochrome c binds to inositol $(1,4,5)$ trisphosphate receptors, amplifying calciumdependent apoptosis," Nature Cell Biology, vol. 5, no. 12, pp. 1051-1061, 2003.

[39] I. R. Boldogh and L. A. Pon, "Interactions of mitochondria with the actin cytoskeleton," Biochimica et Biophysica Acta, vol. 1763, no. 5-6, pp. 450-462, 2006.

[40] D. G. Breckenridge, M. Germain, J. P. Mathai, M. Nguyen, and G. C. Shore, "Regulation of apoptosis by endoplasmic reticulum pathways," Oncogene, vol. 22, no. 53, pp. 8608 8618, 2003.

[41] R. E. Milner, K. S. Famulski, and M. Michalak, "Calcium binding proteins in the sarcoplasmic/endoplasmic reticulum of muscle and nonmuscle cells," Molecular and Cellular Biochemistry, vol. 112, no. 1, pp. 1-13, 1992.

[42] R. K. Reddy, C. Mao, P. Baumeister, R. C. Austin, R. J. Kaufman, and A. S. Lee, "Endoplasmic reticulum chaperone protein GRP78 protects cells from apoptosis induced by topoisomerase inhibitors. Role of ATP binding site in suppression of caspase-7 activation," Journal of Biological Chemistry, vol. 278, no. 23, pp. 20915-20924, 2003.

[43] M. Chami, B. Oulès, G. Szabadkai, R. Tacine, R. Rizzuto, and P. Paterlini-Bréchot, "Role of SERCA1 truncated isoform in the proapoptotic calcium transfer from ER to mitochondria during ER stress," Molecular Cell, vol. 32, no. 5, pp. 641-651, 2008.

[44] S. Doroudgar, D. J. Thuerauf, M. C. Marcinko, P. J. Belmont, and C. C. Glembotski, "Ischemia activates the ATF6 branch of the endoplasmic reticulum stress response," Journal of Biological Chemistry, vol. 284, no. 43, pp. 29735-29745, 2009.

[45] J. Li, M. Ni, B. Lee, E. Barron, D. R. Hinton, and A. S. Lee, "The unfolded protein response regulator GRP78/BiP is required for endoplasmic reticulum integrity and stressinduced autophagy in mammalian cells," Cell Death and Differentiation, vol. 15, no. 9, pp. 1460-1471, 2008.

[46] Y. Fu, J. Li, and A. S. Lee, "GRP78/BiP inhibits endoplasmic reticulum BIK and protects human breast cancer cells against estrogen starvation-induced apoptosis," Cancer Research, vol. 67, no. 8, pp. 3734-3740, 2007.

[47] R. V. Rao, A. Peel, A. Logvinova, et al., "Coupling endoplasmic reticulum stress to the cell death program: role of the ER chaperone GRP78," FEBS Letters, vol. 514, no. 2-3, pp. 122$128,2002$.

[48] A. Matsuzawa, H. Nishitoh, K. Tobiume, K. Takeda, and H. Ichijo, "Physiological roles of ASK1-mediated signal transduction in oxidative stress- and endoplasmic reticulum stress-induced apoptosis: advanced findings from ASK1 knockout mice," Antioxidants and Redox Signaling, vol. 4, no. 3, pp. 415-425, 2002.

[49] H. Shiraishi, H. Okamoto, A. Yoshimura, and H. Yoshida, "ER stress-induced apoptosis and caspase-12 activation occurs downstream of mitochondrial apoptosis involving Apaf-1," Journal of Cell Science, vol. 119, no. 19, pp. 39583966, 2006.

[50] N. Morishima, K. Nakanishi, H. Takenouchi, T. Shibata, and Y. Yasuhiko, "An endoplasmic reticulum stress-specific caspase cascade in apoptosis. Cytochrome c-independent activation of caspase- 9 by caspase-12," Journal of Biological Chemistry, vol. 277, no. 37, pp. 34287-34294, 2002.
[51] S.-J. Kim, Z. Zhang, E. Hitomi, Y.-C. Lee, and A. B. Mukherjee, "Endoplasmic reticulum stress-induced caspase4 activation mediates apoptosis and neurodegeneration in INCL," Human Molecular Genetics, vol. 15, no. 11, pp. 18261834, 2006.

[52] M. Klee, K. Pallauf, S. Alcalá, A. Fleischer, and F. X. PimentelMuiños, "Mitochondrial apoptosis induced by BH3-only molecules in the exclusive presence of endoplasmic reticular Bak," EMBO Journal, vol. 28, no. 12, pp. 1757-1768, 2009.

[53] D. J. McConkey, P. Nicotera, P. Hartzell, G. Bellomo, A. H. Wyllie, and S. Orrenius, "Glucocorticoids activate a suicide process in thymocytes through an elevation of cytosolic $\mathrm{Ca}^{2+}$ concentration," Archives of Biochemistry and Biophysics, vol. 269, no. 1, pp. 365-370, 1989.

[54] L. Magnelli, M. Cinelli, A. Turchetti, and V. P. Chiarugi, "Apoptosis induction in 32D cells by IL-3 withdrawal is preceded by a drop in the intracellular calcium level," Biochemical and Biophysical Research Communications, vol. 194, no. 3, pp. 1394-1397, 1993.

[55] O. Thastrup, P. J. Cullen, B. K. Drobak, M. R. Hanley, and A. P. Dawson, "Thapsigargin, a tumor promoter, discharges intracellular $\mathrm{Ca}^{2+}$ stores by specific inhibition of the endoplasmic reticulum $\mathrm{Ca}^{2+}$-ATPase," Proceedings of the National Academy of Sciences of the United States of America, vol. 87, no. 7, pp. 2466-2470, 1990.

[56] H. He, M. Lam, T. S. McCormick, and C. W. Distelhorst, "Maintenance of calcium homeostasis in the endoplasmic reticulum by Bcl- 2," Journal of Cell Biology, vol. 138, no. 6, pp. 1219-1228, 1997.

[57] I. Yoshida, A. Monji, K. Tashiro, K. Nakamura, R. Inoue, and S. Kanba, "Depletion of intracellular $\mathrm{Ca}^{2+}$ store itself may be a major factor in thapsigargin-induced ER stress and apoptosis in PC12 cells," Neurochemistry International, vol. 48, no. 8, pp. 696-702, 2006.

[58] M. K. T. Squier, A. C. K. Miller, A. M. Malkinson, and J. J. Cohen, "Calpain activation in apoptosis," Journal of Cellular Physiology, vol. 159, no. 2, pp. 229-237, 1994.

[59] D. R. Dowd, P. N. MacDonald, B. S. Komm, M. R. Haussler, and R. Miesfeld, "Evidence for early induction of calmodulin gene expression in lymphocytes undergoing glucocorticoidmediated apoptosis," Journal of Biological Chemistry, vol. 266, no. 28, pp. 18423-18426, 1991.

[60] M. G. Jeschke, G. G. Gauglitz, J. Song, et al., "Calcium and ER stress mediate hepatic apoptosis after burn injury," Journal of Cellular and Molecular Medicine, vol. 13, no. 8b, pp. 18571865, 2009.

[61] D. N. Criddle, J. V. Gerasimenko, H. K. Baumgartner, et al., "Calcium signalling and pancreatic cell death: apoptosis or necrosis?" Cell Death and Differentiation, vol. 14, no. 7, pp. 1285-1294, 2007.

[62] L. K. Nutt, J. Chandra, A. Pataer, et al., "Bax-mediated $\mathrm{Ca}^{2+}$ mobilization promotes cytochrome c release during apoptosis," Journal of Biological Chemistry, vol. 277, no. 23, pp. 20301-20308, 2002.

[63] L. K. Nutt, A. Pataer, J. Pahler, et al., "Bax and Bak promote apoptosis by modulating endoplasmic reticular and mitochondrial $\mathrm{Ca}^{2+}$ stores," Journal of Biological Chemistry, vol. 277, no. 11, pp. 9219-9225, 2002.

[64] C. Cerella, C. Mearelli, S. Coppola, et al., "Sequential phases of $\mathrm{Ca}^{2+}$ alterations in pre-apoptotic cells," Apoptosis, vol. 12, no. 12, pp. 2207-2219, 2007.

[65] C. Cerella, C. Mearelli, M. De Nicola, et al., "Analysis of calcium changes in endoplasmic reticulum during apoptosis by the fluorescent indicator chlortetracycline," Annals of the New York Academy of Sciences, vol. 1099, pp. 490-493, 2007. 
[66] S. Coppola and L. Ghibelli, "GSH extrusion and the mitochondrial pathway of apoptotic signalling," Biochemical Society Transactions, vol. 28, no. 2, pp. 56-61, 2000.

[67] M. E. Peter and P. H. Krammer, "Mechanisms of CD95 (APO-1/Fas)-mediated apoptosis," Current Opinion in Immunology, vol. 10, no. 5, pp. 545-551, 1998.

[68] M. D’Alessio, M. De Nicola, S. Coppola, et al., "Oxidative Bax dimerization promotes its translocation to mitochondria independently of apoptosis," FASEB Journal, vol. 19, no. 11, pp. 1504-1506, 2005.

[69] C. Nie, C. Tian, L. Zhao, P. X. Petit, M. Mehrpour, and Q. Chen, "Cysteine 62 of Bax is critical for its conformational activation and its proapoptotic activity in response to $\mathrm{H}_{2} \mathrm{O}_{2}$ induced apoptosis," Journal of Biological Chemistry, vol. 283, no. 22, pp. 15359-15369, 2008.

[70] G. Gao and Q. P. Dou, "N-terminal cleavage of Bax by calpain generates a potent proapoptotic $18-\mathrm{kDa}$ fragment that promotes $\mathrm{Bcl}-2$-independent cytochrome $\mathrm{C}$ release and apoptotic cell death," Journal of Cellular Biochemistry, vol. 80, no. 1, pp. 53-72, 2000.

[71] Z. Pan, M. B. Bhat, A.-L. Nieminen, and J. Ma, "Synergistic movements of $\mathrm{Ca}^{2+}$ and Bax in cells undergoing apoptosis," Journal of Biological Chemistry, vol. 276, no. 34, pp. 3225732263, 2001.

[72] Q. Chen, B. Gong, and A. Almasan, "Distinct stages of cytochrome $c$ release from mitochondria: evidence for a feedback amplification loop linking caspase activation to mitochondrial dysfunction in genotoxic stress induced apoptosis," Cell Death and Differentiation, vol. 7, no. 2, pp. 227233, 2000.

[73] S. Desagher, A. Osen-Sand, A. Nichols, et al., "Bid-induced conformational change of Bax is responsible for mitochondrial cytochrome c release during apoptosis," Journal of Cell Biology, vol. 144, no. 5, pp. 891-901, 1999.

[74] C. P. Baines, R. A. Kaiser, N. H. Purcell, et al., "Loss of cyclophilin D reveals a critical role for mitochondrial permeability transition in cell death," Nature, vol. 434, no. 7033, pp. 658-662, 2005.

[75] A. C. Schinzel, O. Takeuchi, Z. Huang, et al., "Cyclophilin D is a component of mitochondrial permeability transition and mediates neuronal cell death after focal cerebral ischemia," Proceedings of the National Academy of Sciences of the United States of America, vol. 102, no. 34, pp. 12005-12010, 2005.

[76] R. A. Eliseev, G. Filippov, J. Velos, et al., "Role of cyclophilin $\mathrm{D}$ in the resistance of brain mitochondria to the permeability transition," Neurobiology of Aging, vol. 28, no. 10, pp. 15321542, 2007.

[77] E. M. Shevach, "The effects of cyclosporin A on the immune system," Annual Review of Immunology, vol. 3, pp. 397-423, 1985.

[78] Y. Tsujimoto and S. Shimizu, "Role of the mitochondrial membrane permeability transition in cell death," Apoptosis, vol. 12, no. 5, pp. 835-840, 2007.

[79] J. E. Kokoszka, K. G. Waymire, S. E. Levy, et al., "The ADP/ATP translocator is not essential for the mitochondrial permeability transition pore," Nature, vol. 427, pp. 461-465, 2004.

[80] D. Zhang and J. S. Armstrong, "Bax and the mitochondrial permeability transition cooperate in the release of cytochrome c during endoplasmic reticulum-stress-induced apoptosis," Cell Death and Differentiation, vol. 14, no. 4, pp. 703-715, 2007.
[81] R. Kumarswamy and S. Chandna, "Putative partners in Bax mediated cytochrome-c release: ANT, CypD, VDAC or none of them?" Mitochondrion, vol. 9, no. 1, pp. 1-8, 2009.

[82] D. J. Kane, T. Ord, R. Anton, and D. E. Bredesen, "Expression of bcl-2 inhibits necrotic neural cell death," Journal of Neuroscience Research, vol. 40, no. 2, pp. 269-275, 1995.

[83] S. Matsuyama, S. L. Schendel, Z. Xie, and J. C. Reed, "Cytoprotection by $\mathrm{Bcl}-2$ requires the pore-forming and helices," Journal of Biological Chemistry, vol. 273, no. 47, pp. 30995-31001, 1998.

[84] M. Saito, S. J. Korsmeyer, and P. H. Schlesinger, "BAXdependent transport of cytochrome $\mathrm{C}$ reconstituted in pure liposomes," Nature Cell Biology, vol. 2, no. 8, pp. 553-555, 2000.

[85] K. Kandasamy, S. M. Srinivasula, E. S. Alnemri, et al., "Involvement of proapoptotic molecules Bax and Bak in tumor necrosis factor-related apoptosis-inducing ligand (TRAIL)-induced mitochondrial disruption and apoptosis: differential regulation of cytochrome $\mathrm{c}$ and Smac/DIABLO release," Cancer Research, vol. 63, no. 7, pp. 1712-1721, 2003.

[86] M. Lam, G. Dubyak, L. Chen, G. Nunez, R. L. Miesfeld, and C. W. Distelhorst, "Evidence that BCL-2 represses apoptosis by regulating endoplasmic reticulum-associated $\mathrm{Ca}^{2+}$ fluxes," Proceedings of the National Academy of Sciences of the United States of America, vol. 91, no. 14, pp. 6569-6573, 1994.

[87] C. J. Hanson, M. D. Bootman, C. W. Distelhorst, R. J. H. Wojcikiewicz, and H. L. Roderick, "Bcl-2 suppresses $\mathrm{Ca}^{2+}$ release through inositol 1,4,5-trisphosphate receptors and inhibits $\mathrm{Ca}^{2+}$ uptake by mitochondria without affecting ER calcium store content," Cell Calcium, vol. 44, no. 3, pp. 324338, 2008.

[88] W.-X. Zong, C. Li, G. Hatzivassiliou, et al., "Bax and Bak can localize to the endoplasmic reticulum to initiate apoptosis," Journal of Cell Biology, vol. 162, no. 1, pp. 59-69, 2003.

[89] S. L. Schendel, M. Montal, and J. C. Reed, "Bcl-2 family proteins as ion-channels," Cell Death and Differentiation, vol. 5, no. 5, pp. 372-380, 1998.

[90] M. Chami, A. Prandini, M. Campanella, et al., "Bcl-2 and bax exert opposing effects on $\mathrm{Ca}^{2+}$ signaling, which do not depend on their putative pore-forming region," Journal of Biological Chemistry, vol. 279, no. 52, pp. 54581-54589, 2004.

[91] S. A. Oakes, L. Scorrano, J. T. Opferman, et al., "Proapoptotic BAX and BAK regulate the type 1 inositol trisphosphate receptor and calcium leak from the endoplasmic reticulum," Proceedings of the National Academy of Sciences of the United States of America, vol. 102, no. 1, pp. 105-110, 2005.

[92] S. Orrenius and P. Nicotera, "The calcium ion and cell death," Journal of Neural Transmission, Supplement, no. 43, pp. 1-11, 1994.

[93] M. K. T. Squier and J. J. Cohen, "Calpain, an upstream regulator of thymocyte apoptosis," Journal of Immunology, vol. 158, no. 8, pp. 3690-3697, 1997.

[94] R. Siman, M. Baudry, and G. Lynch, "Brain fodrin: substrate for calpain I, an endogenous calcium-activated protease," Proceedings of the National Academy of Sciences of the United States of America, vol. 81, no. 11, pp. 3572-3576, 1984.

[95] S. J. Martin, G. A. O’Brien, W. K. Nishioka, et al., "Proteolysis of fodrin (non-erythroid spectrin) during apoptosis," Journal of Biological Chemistry, vol. 270, no. 12, pp. 6425-6428, 1995.

[96] A. M. G. Robertson, C. C. Bird, A. W. Waddell, and A. R. Currie, "Morphological aspects of glucocorticoidinduced cell death in human lymphoblastoid cells," Journal of Pathology, vol. 126, no. 3, pp. 181-187, 1978. 
[97] K. Shiraishi, K. Naito, and K.-I. Yoshida, "Inhibition of calpain but not caspase protects the testis against injury after experimental testicular torsion of rat," Biology of Reproduction, vol. 63, no. 5, pp. 1538-1548, 2000.

[98] J. Varghese, G. Radhika, and A. Sarin, "The role of calpain in caspase activation during etoposide induced apoptosis in T cells," European Journal of Immunology, vol. 31, no. 7, pp. 2035-2041, 2001.

[99] L. Ghibelli, F. Mengoni, M. Lichtner, et al., "Anti-apoptotic effect of HIV protease inhibitors via direct inhibition of calpain," Biochemical Pharmacology, vol. 66, no. 8, pp. 15051512, 2003.

[100] J. Wu, T. Liu, J. Xie, F. Xin, and L. Guo, "Mitochondria and calpains mediate caspase-dependent apoptosis induced by doxycycline in HeLa cells," Cellular and Molecular Life Sciences, vol. 63, no. 7-8, pp. 949-957, 2006.

[101] Y. Wang, N. S. Kim, X. Li, et al., "Calpain activation is not required for AIF translocation in PARP-1-dependent cell death (parthanatos)," Journal of Neurochemistry, vol. 110, no. 2, pp. 687-696, 2009.

[102] N. J. Waterhouse, D. M. Finucane, D. R. Green, et al., "Calpain activation is upstream of caspases in radiationinduced apoptosis," Cell Death and Differentiation, vol. 5, no. 12, pp. 1051-1061, 1998.

[103] K. Blomgren, C. Zhu, X. Wang, et al., "Synergistic activation of caspase- 3 by m-calpain after neonatal hypoxia-ischemia: a mechanism of "pathological apoptosis"?" Journal of Biological Chemistry, vol. 276, no. 13, pp. 10191-10198, 2001.

[104] D. E. Wood, A. Thomas, L. A. Devi, et al., "Bax cleavage is mediated by calpain during drug-induced apoptosis," Oncogene, vol. 17, no. 9, pp. 1069-1078, 1998.

[105] M. Marani, T. Tenev, D. Hancock, J. Downward, and N. R. Lemoine, "Identification of novel isoforms of the BH3 domain protein bim which directly activate Bax to trigger apoptosis," Molecular and Cellular Biology, vol. 22, no. 11, pp. 3577-3589, 2002.

[106] J. E. Chipuk, T. Kuwana, L. Bouchier-Hayes, et al., "Direct activation of Bax by $\mathrm{p} 53$ mediates mitochondrial membrane permeabilization and apoptosis," Science, vol. 303, no. 5660, pp. 1010-1014, 2004.

[107] T. Ozaki, T. Yamashita, and S. Ishiguro, "ERp57-associated mitochondrial $\mu$-calpain truncates apoptosis-inducing factor," Biochimica et Biophysica Acta, vol. 1783, no. 10, pp. 1955-1963, 2008.

[108] T. Ozaki, T. Yamashita, and S. Ishiguro, "Mitochondrial mcalpain plays a role in the release of truncated apoptosisinducing factor from the mitochondria," Biochimica et Biophysica Acta, vol. 1793, no. 12, pp. 1848-1859, 2009.

[109] T. Nakagawa and J. Yuan, "Cross-talk between two cysteine protease families: activation of caspase- 12 by calpain in apoptosis," Journal of Cell Biology, vol. 150, no. 4, pp. 887894, 2000.

[110] N. Bizat, J.-M. Hermel, S. Humbert, et al., "In vivo calpain/caspase cross-talk during 3-nitropropionic acidinduced striatal degeneration: implication of a calpainmediated cleavage of active caspase-3," Journal of Biological Chemistry, vol. 278, no. 44, pp. 43245-43253, 2003.

[111] A. K. Sharma and B. Rohrer, "Calcium-induced calpain mediates apoptosis via caspase-3 in a mouse photoreceptor cell line," Journal of Biological Chemistry, vol. 279, no. 34, pp. 35564-35572, 2004.

[112] J. Gafni, X. Cong, S. F. Chen, B. W. Gibson, and L. M. Ellerby, "Calpain-1 cleaves and activates caspase-7," Journal of Biological Chemistry, vol. 284, no. 37, pp. 25441-25449, 2009.

[113] C. Volbracht, B. T. Chua, C. P. Ng, B. A. Bahr, W. Hong, and P. Li, "The critical role of calpain versus caspase activation in excitotoxic injury induced by nitric oxide," Journal of Neurochemistry, vol. 93, no. 5, pp. 1280-1292, 2005.

[114] M. E. Feder and G. E. Hofmann, "Heat-shock proteins, molecular chaperones, and the stress response: evolutionary and ecological physiology," Annual Review of Physiology, vol. 61, pp. 243-282, 1999.

[115] K. J. A. Davies, "Oxidative stress, antioxidant defenses, and damage removal, repair, and replacement systems," IUBMB Life, vol. 50, no. 4-5, pp. 279-289, 2000.

[116] G. H. Malthankar-Phatak, A. B. Patel, Y. Xia, et al., "Effects of continuous hypoxia on energy metabolism in cultured cerebro-cortical neurons," Brain Research, vol. 1229, pp. 147154, 2008.

[117] C. Kang and L. Avery, "To be or not to be, the level of autophagy is the question: dual roles of autophagy in the survival response to starvation," Autophagy, vol. 4, no. 1, pp. 82-84, 2008.

[118] K. C. Kregel, "Invited review: heat shock proteins: modifying factors in physiological stress responses and acquired thermotolerance," Journal of Applied Physiology, vol. 92, no. 5, pp. 2177-2186, 2002.

[119] K. Przyklenk, B. Z. Simkhovich, B. Bauer, et al., "Cellular mechanisms of infarct size reduction with ischemic preconditioning. Role of calcium?" Annals of the New York Academy of Sciences, vol. 874, pp. 192-210, 1999.

[120] M. Høyer-Hansen, L. Bastholm, P. Szyniarowski, et al., "Control of macroautophagy by calcium, calmodulin-dependent kinase kinase- $\beta$, and Bcl-2," Molecular Cell, vol. 25, no. 2, pp. 193-205, 2007.

[121] H.-U. Simon, "Neutrophil apoptosis pathways and their modifications in inflammation," Immunological Reviews, vol. 193, pp. 101-110, 2003.

[122] F. Balkwill and A. Mantovani, "Inflammation and cancer: back to Virchow?" Lancet, vol. 357, no. 9255, pp. 539-545, 2001.

[123] H. Miyawaki, X. Zhou, and M. Ashraf, "Calcium preconditioning elicits strong protection against ischemic injury via protein kinase C signaling pathway," Circulation Research, vol. 79, no. 1, pp. 137-146, 1996.

[124] Z. Moneer, I. Pino, E. J. A. Taylor, et al., "Different phospholipase-C-coupled receptors differentially regulate capacitative and non-capacitative $\mathrm{Ca}^{2+}$ entry in A7r5 cells," Biochemical Journal, vol. 389, no. 3, pp. 821-829, 2005.

[125] V. Calabrese, C. Cornelius, E. Rizzarelli, J. B. Owen, A. T. Dinkova-Kostova, and D. A. Butterfield, "Nitric oxide in cell survival: a janus molecule," Antioxidants \& Redox Signaling, vol. 11, no. 11, pp. 2717-2739, 2009.

[126] C. Fanelli, S. Coppola, R. Barone, et al., "Magnetic fields increase cell survival by inhibiting apoptosis via modulation of $\mathrm{Ca}^{2+}$ influx," FASEB Journal, vol. 13, no. 1, pp. 95-102, 1999.

[127] L. Ghibelli, C. Cerella, S. Cordisco, et al., "NMR exposure sensitizes tumor cells to apoptosis," Apoptosis, vol. 11, no. 3, pp. 359-365, 2006.

[128] C. Colussi, M. C. Albertini, S. Coppola, S. Rovidati, F. Galli, and L. Ghibelli, " $\mathrm{H}_{2} \mathrm{O}_{2}$-induced block of glycolysis as an active ADP-ribosylation reaction protecting cells from apoptosis," FASEB Journal, vol. 14, no. 14, pp. 2266-2276, 2000. 
[129] R. Martínez-Zaguilán and D. E. Wesson, "Regulation of endoplasmic reticulum-Ca-ATPase by glycolysis in eukaryotic cells," Mineral and Electrolyte Metabolism, vol. 22, no. 56, pp. 318-335, 1996.

[130] K. Nakamura, E. Bossy-Wetzel, K. Burns, et al., "Changes in endoplasmic reticulum luminal environment affect cell sensitivity to apoptosis," Journal of Cell Biology, vol. 150, no. 4, pp. 731-740, 2000.

[131] P. Pinton, D. Ferrari, E. Rapizzi, F. Di Virgilio, T. Pozzan, and R. Rizzuto, "The $\mathrm{Ca}^{2+}$ concentration of the endoplasmic reticulum is a key determinant of ceramide-induced apoptosis: significance for the molecular mechanism of Bcl-2 action," EMBO Journal, vol. 20, no. 11, pp. 2690-2701, 2001.

[132] C. Cerella, M. D’Alessio, M. De Nicola, A. Magrini, A. Bergamaschi, and L. Ghibelli, "Cytosolic and endoplasmic reticulum $\mathrm{Ca}^{2+}$ concentrations determine the extent and the morphological type of apoptosis, respectively," Annals of the New York Academy of Sciences, vol. 1010, pp. 74-77, 2003. 

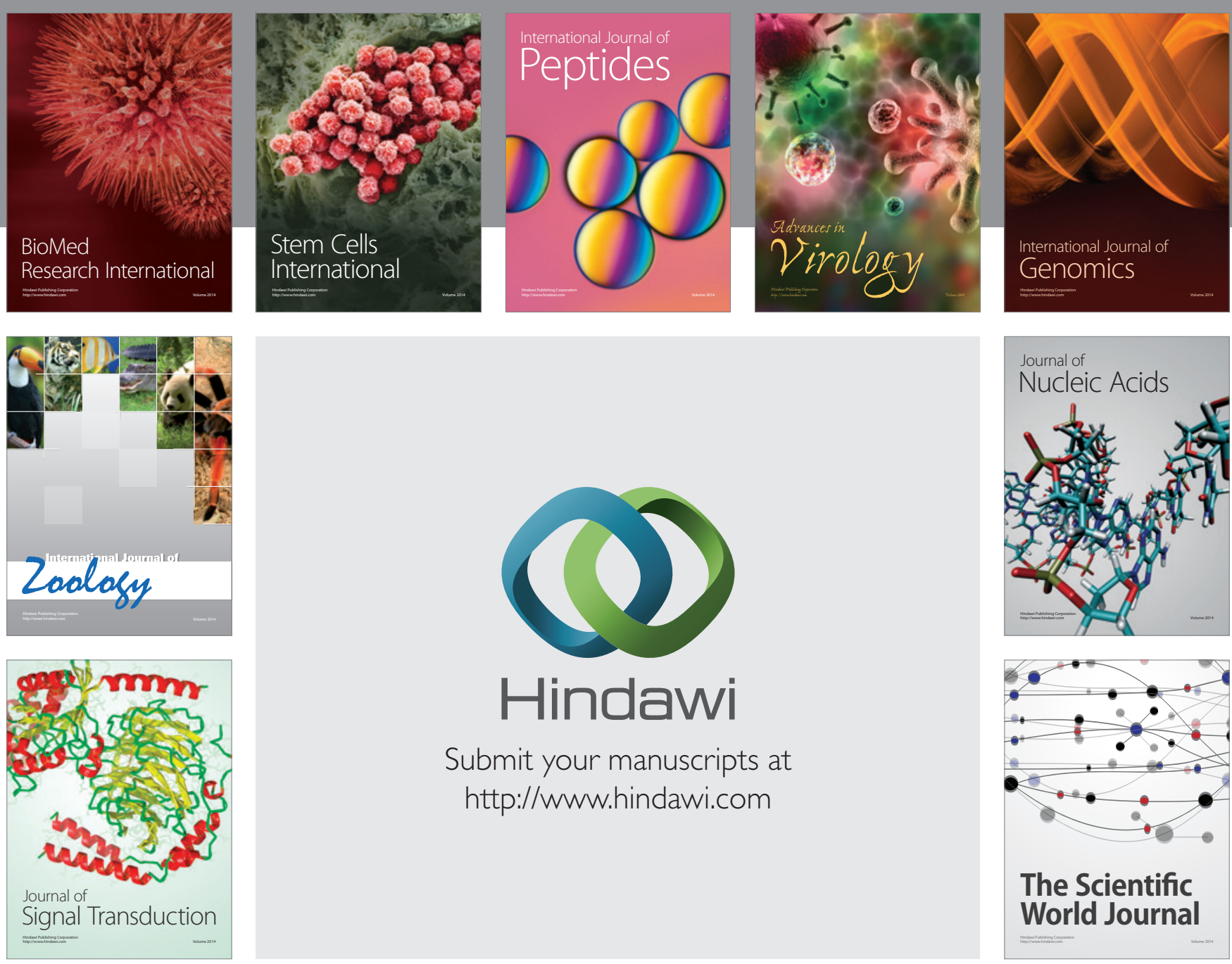

Submit your manuscripts at

http://www.hindawi.com
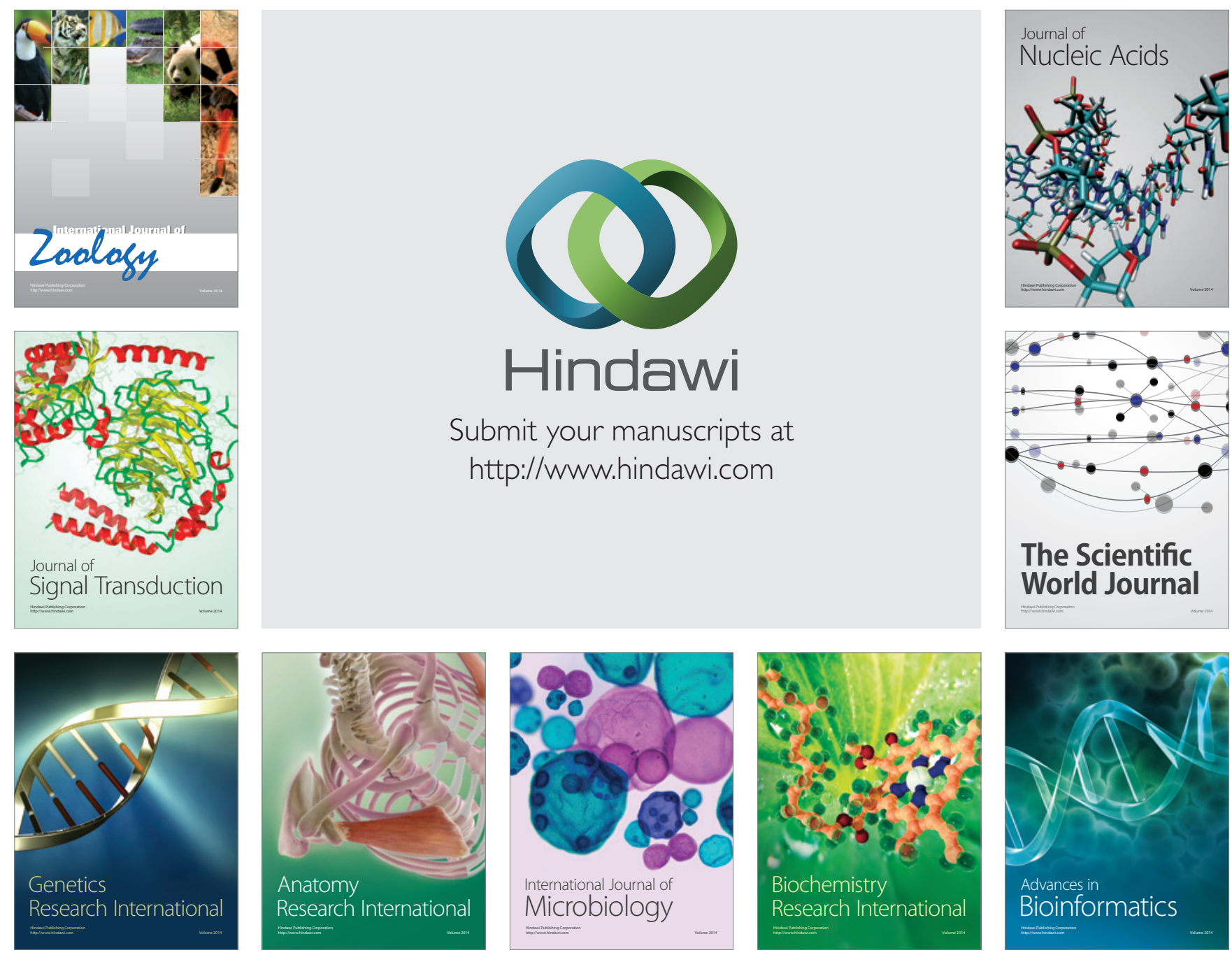

The Scientific World Journal
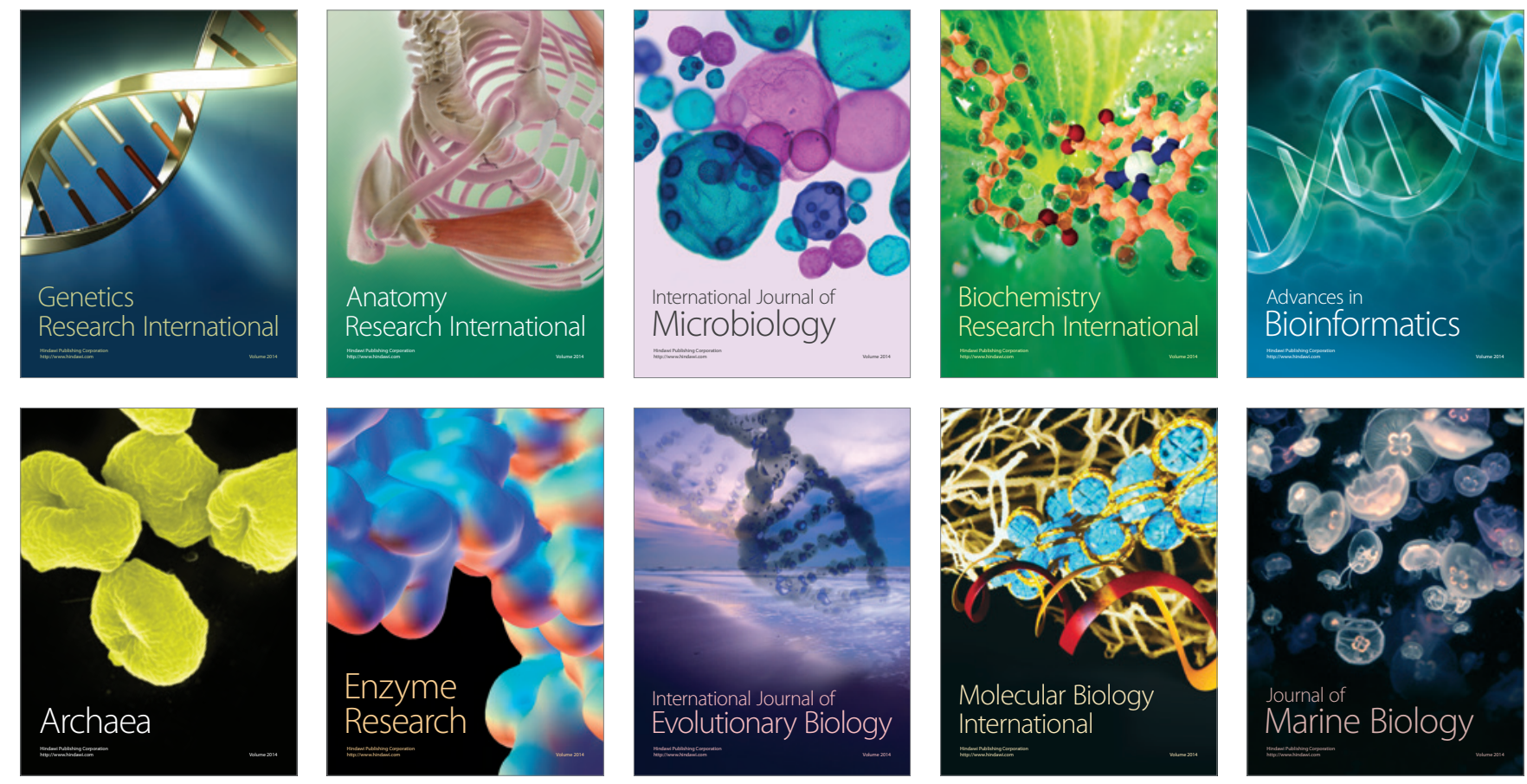